\title{
Review
}

\section{Polycystic Ovary Syndrome: An Evolutionary Adaptation to Lifestyle and the Environment}

\author{
Jim Parker ${ }^{{ }^{*}}$, Claire $\mathrm{O}^{\prime}$ Brien $^{2}$, Jason Hawrelak ${ }^{3}$ and Felice L Gersh ${ }^{4}$ \\ 1 School of Medicine, University of Wollongong, Australia; jimparker@ozemail.com.au \\ 2 Faculty of Science and Technology, University of Canberra, Australia; clairelouiseobrien@icloud.com \\ 3 College of Health and Medicine, University of Tasmania, Australia; Jason.Hawrelak@utas.edu.au \\ 4 College of Medicine, University of Arizona, Irvine, California, USA; felicegersh@yahoo.com \\ * Correspondence: jimparker@ozemail.com.au
}

\begin{abstract}
Polycystic ovary syndrome (PCOS) is increasingly recognized as a complex metabolic disorder that manifests in genetically susceptible women following a range of negative exposures to nutritional and environmental factors related to contemporary lifestyle. The hypothesis that PCOS phenotypes are derived from a mismatch between ancient genetic survival mechanisms and modern lifestyle practices is supported by a diversity of research findings. The proposed evolutionary model of the pathogenesis of PCOS incorporates evidence related to evolutionary theory, genetic studies, in-utero developmental epigenetic programming, transgenerational inheritance, metabolic features including insulin resistance, obesity and the apparent paradox of lean phenotypes, reproductive effects and subfertility, the impact of the microbiome and dysbiosis, endocrine disrupting chemical exposure, and the influence of lifestyle factors such as poor quality diet and physical inactivity. Based on these premises, the diverse lines of research are synthesized into a composite evolutionary model of the pathogenesis of PCOS. It is hoped that this model will assist clinicians and patients to understand the importance of lifestyle interventions in the prevention and management of PCOS and provide a conceptual framework for future research. It is appreciated that this theory represents a synthesis of the current evidence and that it is expected to evolve and change over time.
\end{abstract}

Keywords: polycystic ovary syndrome; evolution; insulin resistance; infertility; toxins, endocrine disrupting chemicals; environment; lifestyle; diet

\section{Introduction}

It is widely accepted that there is a global epidemic of lifestyle-related chronic diseases, such as obesity and diabetes, that are underpinned by reversible metabolic dysfunction in the majority of individuals affected (1-3). It is also recognized that many of these chronic diseases may share a similar pathogenesis involving the interaction of genetic and environmental factors that manifest in overlapping pathophysiological features (4-6). The revised International Guidelines for the assessment and management of women with PCOS, emphasise that the associated metabolic dysfunction and symptoms should initially be addressed via lifestyle interventions (7).

Evolutionary medicine is an emerging discipline involving the study of evolutionary processes that relate to human traits and diseases and the incorporation of these findings 
into the practice of medicine (8). Evolutionary medicine brings together interdisciplinary research to inform clinical medicine based on the influence of evolutionary history on human health and disease (9). Previous utilization of the principles of evolutionary medicine has been limited to monogenetic diseases (cystic fibrosis, sickle cell anaemia, phenylketonuria and many others), drug resistance of microorganisms, tumour growth and chemoresistance (8). Future insights into the application of evolutionary research offers the potential to improve and personalize the established medical and scientific approaches to complex chronic diseases like type 2 diabetes, metabolic syndrome and $\operatorname{PCOS}(5,9)$.

The evolutionary origins of complex chronic diseases incorporate considerations of relative reproductive fitness, mismatch between our biological past and modern environment, trade-offs involving combinations of genetic traits, and evolutionary conflicts $(8,10)$. These evolutionary factors are relevant when analysing the contributors to the pathogenesis of PCOS in modern and modernising societies, that result in a mismatch between our rapid cultural evolution with our slow biological evolution $(11,12)$. The unique cultural evolution of humans does not have a plausible analogue in most other species and is increasingly recognised to play a significant role in the pathogenesis of metabolic diseases such as PCOS (5,13-17).

Polycystic ovary syndrome is a complex multisystem condition with metabolic, endocrine, psychological, fertility and pregnancy-related implications at all stages of life $(7,18)$. The majority of women with PCOS manifest multiple metabolic features including obesity, insulin resistance (IR), hyperlipidaemia and hyperandrogenism $(19,20)$. PCOS results in an increased risk of developing metabolic disease (type 2 diabetes, non-alcoholic fatty liver disease (NAFLD) and metabolic syndrome), cardiovascular disease, cancer, a wide array of pregnancy complications (deep venous thrombosis, pre-eclampsia, gestational diabetes, macrosomia, growth restriction, miscarriage, stillbirth and preterm labour) and psychological problems (anxiety, depression) (6,21-25). PCOS is part of a cluster of inter-related metabolic conditions and makes a significant contribution to the chronic disease epidemic.

Extensive research suggests that the aetiology of PCOS involves an interaction between environmental factors and gene variants, although it has been suggested that genetic factors contribute less than $10 \%$ to disease susceptibility (26-28). A large number of genetic and genome-wide association studies (GWAS) have identified common gene loci associated with PCOS phenotypes in different ethnic populations (29-31). These appear to be normal gene variants or polymorphisms, given the frequency and type of genes that have been identified. PCOS is therefore viewed as a polygenic trait that results from an interaction between susceptible genomic variants and the environment.

PCOS effects upward of $10 \%$ of reproductive-aged women, estimated at over 200 million women worldwide $(32,33)$. PCOS is thought to be increasing in incidence in both developing and developed nations as a result of lifestyle-related changes in diet quality, reduced physical activity, ubiquitous environmental endocrine disrupting chemicals (EDC), altered light exposures, sleep disturbance, heightened levels of stress and other 
environmental factors (11,34-38). These factors, and the high prevalence of PCOS, suggest that there could be an evolutionary basis for the syndrome $(15,16,39)$. Evolutionary medicine has changed the paradigm for understanding PCOS, acknowledging many of the contributing lifestyle and environmental factors that facilitate the observed metabolic and clinical features and that are also shared with related metabolic diseases (8). These "mismatch disorders" are estimated to make a significant contribution to chronic disease in developed countries and a growing proportion of disability and death in developing nations (3). According to the Global Burden of Disease Study, the human diet is now the leading risk factor for morbidity and mortality worldwide (3). In keeping with these findings, diet is recognized as one of the major contributors to the growing prevalence of PCOS globally $(7,40)$.

Dietary and environmental factors are hypothesized to have an impact on developmental programming of susceptible gene variants in women with PCOS (41-43). Extensive experimental evidence suggests that prenatal androgen exposure may play a role in the pathogenesis of PCOS-like syndromes in animal models $(19,44-46)$. The discovery of naturally-occurring PCOS phenotypes in non-human primates supports a survival advantage of a hyperandrogenic, insulin resistant phenotype with delayed fertility (47). In humans, the origin of excess androgens may be from maternal, fetal or placental sources. In addition, emerging and concerning evidence suggests that EDC may contribute to altered fetal programming and play a role in the pathogenesis of PCOS $(41,48)$.

In-utero genomic programming of metabolic and endocrine pathways can increase the susceptibility of offspring to develop PCOS following exposure to specific nutritional and environmental conditions (45). This view of the pathogenesis of PCOS is consistent with the Developmental Origins of Health and Disease (DOHaD) model proposed by Neel (49). Postnatal exposure to lifestyle and environmental factors, such as poor-quality diet and EDC, may activate epigenetically programmed pathways that further promote the observed features of PCOS. Dietary and lifestyle interventions have demonstrated that many of the clinical, metabolic and endocrine features of PCOS can be reversed $(7,50,51)$.

Lifestyle-induced changes in the gastrointestinal tract microbiome are another significant factor in the aetiology of PCOS $(52,53)$. Dysbiosis of the gut microbiota has been hypothesised to play a role in increased gastrointestinal permeability, initiating chronic inflammation, IR and hyperandrogenism (40). Numerous studies have reported reduced alpha diversity of the microbiome that has been associated with the metabolic, endocrine and clinical features observed in women with PCOS $(54,55)$. The resulting dysbiosis has been shown to be reversible after interventions aimed at improving diet quality or treatment with probiotics or synbiotics (50,51,56-58).

A unified evolutionary theory of the pathogenesis of PCOS proposes that ancient genetic polymorphisms that were aligned with the environment of that era, resulted in an adaptive survival advantage in offspring in ancestral populations $(14-16,28)$. When these same genetic variants are exposed to modern lifestyle and environmental influences, maladaptive physiological responses occur. The prior advantages of insulin resistance, hyperandrogenism, enhanced energy storage and reduced fertility in ancestral 
populations become pathological and result in the observed features of PCOS in contemporary women (figure 1).

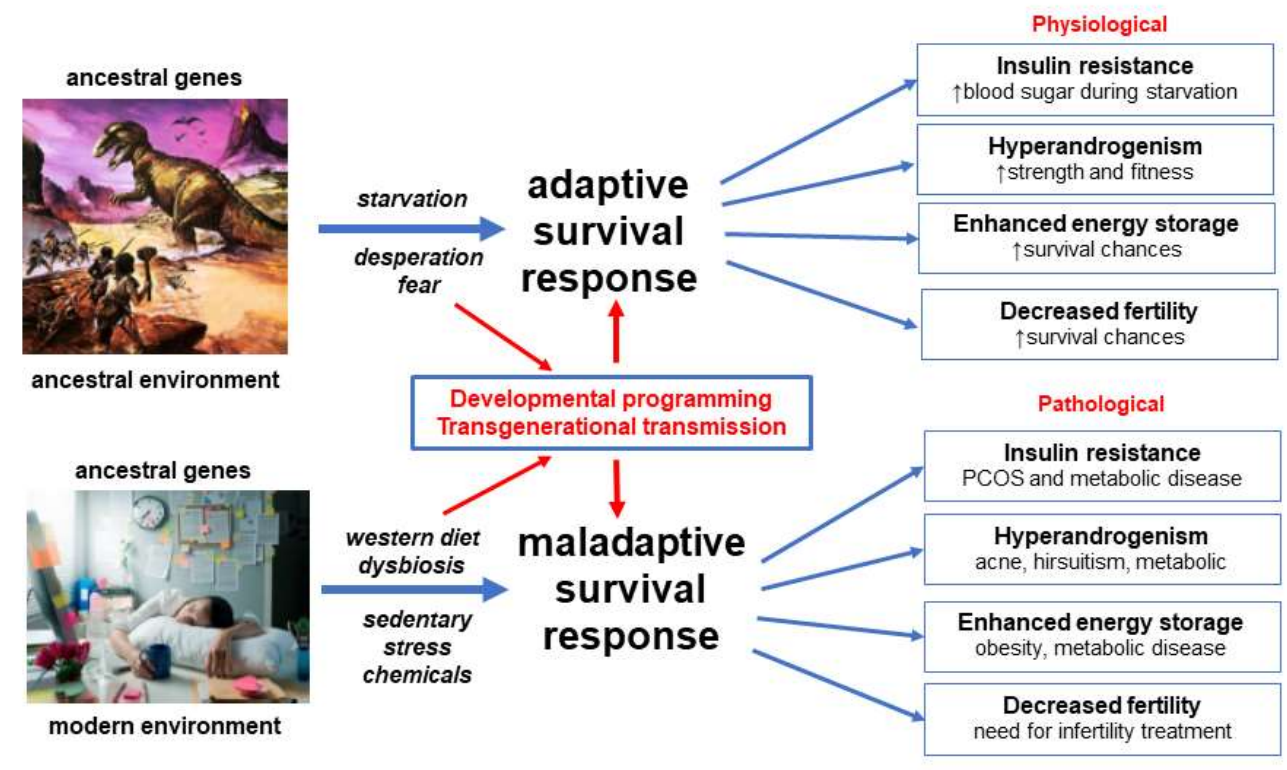

Figure 1. Evolutionary model of the pathogenesis of polycystic ovary syndrome

\section{Materials and Methods}

The literature search focused on research publications related to the pathogenesis of PCOS using the keywords listed above and related mesh terms for data on the evolutionary aspects of PCOS, genetic studies, in-utero developmental epigenetic programming, transgenerational inheritance, metabolic features including insulin resistance, obese and lean PCOS phenotypes, reproductive changes and subfertility, impact of the microbiome and dysbiosis, possible effects of endocrine disrupting chemical exposure and the influence of lifestyle factors such as diet and physical activity. The databases searched included PubMed, Scopus, Cochrane and Google Scholar. Relevant papers were selected and citation searches were performed.

The present manuscript synthesizes the findings into a unified evolutionary model. The following text is presented as a narrative review of factors involved in the pathogenesis of PCOS and is discussed in ten main subject areas that provide the rationale for the development of a unified model. 1. Evolution 2. Genetics 3. Developmental Epigenetic Programming 4. Microbiome and Dysbiosis 5. Insulin resistance 6. Obesity and the lean paradox 7. Environmental Chemical Exposure 8. Lifestyle Contributors to the Pathogenesis of PCOS 9. Conceptual Framework of a Unified Evolutionary Model 10. Explanation to women diagnosed with PCOS.

\section{Pathogenesis of PCOS}

\subsection{Evolution}

The description of PCOS phenotypes can be found in medical records from antiquity and the modern syndrome was described over 80 years ago $(17,59)$. Nevertheless, there is ongoing debate regarding the evolutionary origins of PCOS (15-17,39,60-64). PCOS 
susceptibility alleles may have arisen in our phylogenetic ancestors, in the Hunter-gatherer Paleolithic period of the Stone Age, after the Neolithic Agricultural Revolution or following the Industrial Revolution $(16,17)$. From an evolutionary perspective, nearly all genetic variants that influence disease risk have human-specific origins, but the systems they relate to have ancient roots in our evolutionary ancestors (8). Regardless of the precise timing of the origin of PCOS in humans, the complex metabolic and reproductive gene variants identified in women with PCOS relate to ancient evolutionary-conserved metabolic and reproductive survival pathways $(15,29)$. Although evolutionary hypotheses about disease vulnerability are impossible to prove they have the potential to frame medical thinking and direct scientific research for the proximate causes of disease $(15,60)$.

Multiple hypotheses have been proposed regarding the evolutionary origins of PCOS and related metabolic diseases $(8,60,63)$. These hypotheses are focused on the relative importance of metabolic survival adaptations versus improved reproductive success, or a combination of both. A detailed analysis of these hypotheses, and the complexities of the evolutionary considerations, have been reviewed elsewhere and is beyond the scope of the present review $(8,60)$. One common theme is that PCOS may be viewed as a "conditional phenotype" where a specific set of conditions has unmasked normally unexpressed or partly expressed genetic pathways, which then provide a survival advantage under certain environmental conditions $(14,16)$.

All organisms have physiological adaptive responses to deal with changing environmental conditions (starvation, fasting, physical threat, stress and infection) and the varying demands of internal physiological states (pregnancy, lactation and adolescence) $(14,65)$. It has been proposed that the PCOS phenotype may have been invoked in specific environmental conditions in ancestral populations as a short, medium or even long-term adaptive survival mechanism (15-17). The view of PCOS as a conditional phenotype proposes that these physiological responses become pathological in our modern environment due to factors such as food abundance, reduced physical activity, circadian disruption, stress and environmental chemical exposure. The transgenerational evolutionary theory of the pathogenesis of PCOS encompasses all of the above ideas to explain the observed pathophysiological and clinical features of PCOS (28).

It is generally accepted that almost all pre-industrial societies and animal populations experienced seasonal or unpredictable episodes of food shortage that applied evolutionary pressure to develop metabolic and reproductive adaptive survival responses $(17,49)$. It is also appreciated that metabolic and reproductive pathways are interconnected and involve reciprocal feedback control mechanisms (66-68). During periods of starvation, anorexia or excessive weight gain, reproduction is down-regulated and ovulation becomes irregular or ceases $(69,70)$. Similarly, metabolic function is co-ordinated with the menstrual cycle to ensure optimal physiological conditions for fertilisation, implantation, pregnancy, parturition and lactation (71). Recent research has elaborated on the details of how some of these complex regulatory mechanisms interact by using specific hormonal, nutrient sensing and intracellular signalling networks (72-74). 
Details of the mechanisms underlying the proposed adaptive survival advantages of IR, hyperandrogenism, enhanced energy storage and sub-fertility have been obtained from paleolithic records, animal models and human populations exposed to adverse environmental conditions such as war and famine-inflicted starvation $(14,16,62,63)$. Multiple lines of evidence support the maladaptive response of human populations to rapidly changing nutritional, physical, psychological and cultural environments, in the modern world $(5,11,14,75)$. These "adaptations" result in pathological responses to IR, hyperandrogenism, enhanced energy storage and ovulation (figure 1).

Theories of evolutionary mismatch have also been advanced to explain all of the cluster of metabolic diseases associated with PCOS (type 2 diabetes, metabolic syndrome, NAFLD and cardiovascular disease) and follow the same set of basic principles and explanations $(14,76)$. This common body of evolutionary evidence is supported by the increasing incidence of metabolic-related disease, such as diabetes and obesity, in developed countries and in developing nations adopting a Western diet and lifestyle $(11,77)$. In addition, the demonstrated reversibility of PCOS and related metabolic and biochemical features following changes in diet, increased physical activity and other lifestyle interventions, adds further support to a transgenerational evolutionary model $(50,51)$.

\subsection{Genetics}

The heritable nature of PCOS has been proposed since the 1960's following a range of familial, twin and chromosomal studies (78-80). Cytogenetic studies failed to identify karyotypic abnormalities and genetic studies did not show a monogenic inheritance pattern following examination of candidate genes $(81,82)$. In addition, two or more phenotypes can be present in the same family suggesting that some of the phenotypic differences could be accounted for by variable expression of the same shared genes $(81,83)$.

The mapping of the human genome in 2003 (84) and the publication of the human haplotype map (more than one million single nucleotide polymorphisms of common genetic variants) in 2005 (85), lead to the realisation that most DNA variation is shared by all humans and is inherited as blocks of linked genes (linkage disequilibrium) (86). These advances enabled a revolution in case-control studies and the development of GWAS which map the entire human genome looking for susceptibility genes for complex traits such as obesity, type 2 diabetes and PCOS (81).

The first PCOS GWAS was published in 2010 and demonstrated 11 gene loci associated with PCOS (87). Additional loci have subsequently been found in a number of different ethnic groups $(86,88)$. The first GWAS analysis of quantitative traits was published in 2015 and showed that a variant (rs11031006) was associated with luteinizing hormone levels (88). The largest GWAS included a meta-analysis of 10,074 PCOS cases and 103,164 controls and identified 19 loci that confer risk for PCOS (29). The genes associated with these loci involve gonadotrophin action, ovarian steroidogenesis, insulin resistance and type 2 diabetes susceptibility genes. The first GWAS using electronic health recordlinked biobanks has introduced greater investigative power and identified 2 additional loci (89). These variants were associated with polycystic ovaries and hyperandrogenism 
(rs17186366 near SOD2) and oligomenorrhoea and infertility (rs144248326 near WWTR1) (89). In addition to identifying common gene variants for PCOS phenotypes, finding the same signals (THADA, YAP1 and c9orf3) in Chinese and European populations suggests that PCOS is an ancient trait that was present before humans migrated out of Africa (81).

More recently Mendelian randomization (MR) studies have been used to explore the potential causative association between gene variants identified in GWAS and PCOS $(90,91)$. Many of the gene variants identified in GWAS are located in non-coding regions of DNA (92). The genes or functional DNA elements through which these variants exert their effects are often unknown. Mendelian randomization is a statistical methodology used to jointly analyse GWAS and quantitative gene loci to test for association between gene expression and a trait, due to a shared or potentially causal variant at a specific locus (93). A detailed analysis of MR methodology and the limitations of this statistical tool is beyond the scope of the present review. Although MR studies have the potential to infer causation it is recognised that they also have limitations in PCOS research (90). Nevertheless, preliminary evidence suggests that a number of genes related to obesity, metabolic and reproductive function, may play a causal role in the pathogenesis of PCOS $(90,91)$.

Decades of genetic research has therefore characterised PCOS as a polygenic trait that results from interactions between the environment and susceptible genomic traits $(27,29,79,88)$. The failure to identify a qualitative or monogenic inheritance pattern and the findings from GWAS, MR, familial and twin studies, suggests that the heritability of PCOS is likely to be due to the combination of multiple genes having small effect size, as has been found with obesity and type 2 diabetes (79,80,94-96). Polygenic traits are the result of gene variants that represent one end of the bell-shaped normal distribution curve of continuous variation in a population (97). From an evolutionary perspective, women with PCOS may represent the "metabolic elite" end of the normal distribution curve, being able to efficiently store energy in periods of food abundance and down-regulate fertility in times of food scarcity, or even in anticipation of reduced seasonal food availability as a predictive adaptive response $(16,17,60)$.

The realisation that PCOS is a quantitative trait (phenotype determined by multiple genes and environmental factors) has far-reaching implications for the diagnosis, treatment and prevention of symptoms and pathology associated with PCOS. The implications require a shift in thinking about PCOS as a "disease" to a variation of normal metabolic and reproductive function. This shift invites a change in vocabulary from talking about "disorder" and "risk" to talking about "expression" and "variability" (97). This new understanding supports and reinforces an evolutionary model of the pathogenesis of PCOS. In keeping with this model, multiple lines of evidence suggest that inherited PCOS gene variants are developmentally programmed in a way that primes them for activation by nutritional and environmental factors in postnatal life $(41,42,98)$.

\subsection{Developmental epigenetic programming}

The developmental programming of PCOS represents changes in gene expression that occur during critical periods of fetal development (99). Following fertilisation, most 
parental epigenetic programming is erased and dramatic epigenomic reprogramming occurs (100). This results in transformation of the parental epigenome to the zygote epigenome and determines personalised gene function. Compelling evidence shows that a wide range of maternal, nutritional and environmental factors can effect fetal development during these critical periods of programming $(44,98,99,101,102)$. These include hormones, vitamins, diet-derived metabolites and environmental chemicals $(48,98,103,104)$. In addition, epigenetic reprogramming of germ-line cells can lead to transgenerational inheritance resulting in phenotypic variation or pathology in the absence of continued direct exposure (98).

Experimental studies in primates, sheep, rats and mice show that PCOS-like syndromes can be induced by a range of treatments including androgens, anti-Mullerian hormone and letrozole $(19,44,46)$. Nevertheless, there is significant debate regarding when an animal model qualifies as PCOS-like (105). The model used and the method of induction of PCOS phenotypes therefore needs to be carefully scrutinised when generalising findings from animal research to women with PCOS. The vast majority of animal and human research on the developmental origins of PCOS has focussed on the role of prenatal androgen exposure. This has been extensively reviewed in numerous previous publications $(41,46)$. This research has resulted in a proposed "two hit" hypothesis for the development of PCOS phenotypes $(43,45)$. The "first hit" involves developmental programming of inherited susceptibility genes and the "second hit" arises due to lifestyle and environmental influences in childhood, adolescence and adulthood $(41,106)$.

If PCOS is a quantitative trait involving normal gene variants, as suggested by the evolutionary considerations and findings from genetic research, then the "first hit" may result from normal developmental programming events as occurs with other gene variants (102). According to this hypothesis, the polygenic susceptibility genes would be normally "activated" and "primed" to respond to future maternal and environmental conditions and exposures, as would be the case with many other normal genes (28). In addition, the susceptibility alleles may be "activated" or "functionally enhanced" by a range of maternal and environmental factors, as is usually presumed to be the case in PCOS $(5,14,102)$. This developmental plasticity would provide a mechanism for a predictive adaptive response, based on inputs from the maternal environment that could be used to programme metabolic and reproductive survival pathways, to better prepare the offspring for the future world in which they may be expected to live (107).

Parental lifestyle factors including diet, obesity, smoking and endocrine disrupting chemicals, have all been shown to modulate disease risk later in life $(104,108,109)$. The original description of the fetal origin's hypothesis proposed that poor maternal nutrition would increase fetal susceptibility to the effects of a Western-style diet later in life (49). Subsequent studies have confirmed that maternal exposure to either nutrient excess or deficit, can have long-term consequences for the health of the progeny (104). Evidence from human and animal studies suggests that maternal obesity programs the offspring for increased risk of developing obesity, hyperglycaemia, diabetes, hypertension and metabolic syndrome (108). 
The developmental origins of PCOS may have been due to different factors in ancestral and modern populations $(17,60)$. It has been hypothesised that environmental stress, infection, nutrient deprivation, fetal growth restriction and stress hormone responses may have resulted in maternally-mediated modulation of gene expression in ancestral offspring $(17,110)$. Some of these factors have been investigated and confirmed in modern populations subject to starvation and extreme environmental conditions (111). In contrast, altered fetal programming in modern societies may be secondary to maternal overnutrition, sedentary behaviour, obesity, emotional stress, circadian rhythm disruption, poor gut health or environmental chemical exposure $(35,101,112,113)$. The preconception and pregnancy periods therefore provide a unique opportunity for lifestyle interventions that promote optimal future health for both the mother and the offspring (figure 2).

\section{PCOS and the DOHaD Cycle of Life}

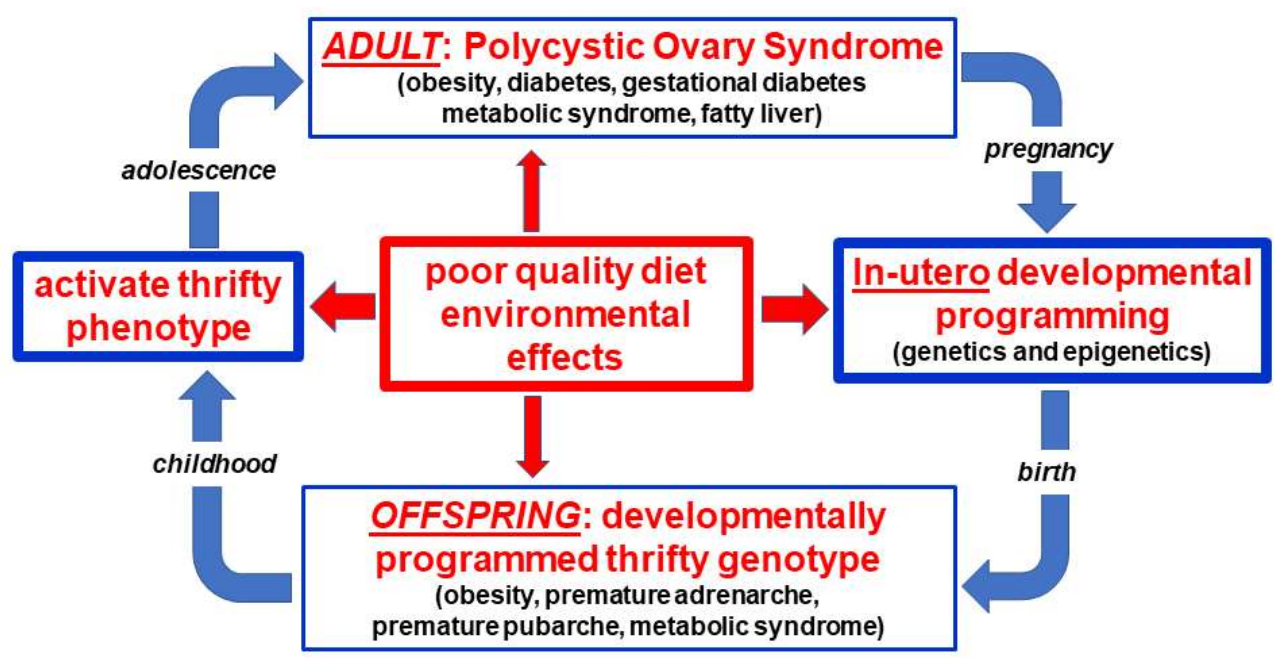

Figure 2. Nutritional and environmental influences throughout the life course and the perpetuation of the transgenerational inheritance of polycystic ovary syndrome

\subsection{Microbiome and Dysbiosis}

The gastrointestinal microbiome is now appreciated to play a central role in human health and disease $(114,115)$. The microbiome is known to co-regulate many physiological functions involving the immune, neuroendocrine and metabolic systems via complex reciprocal feedback mechanisms that operate between the microbial ecosystem and the host $(116,117)$. Evidence from studies in Western populations, Hunter-gatherer societies and phylogenetic studies in other species, have attempted to place the human microbiome into an evolutionary context (118). Although microbes clearly impact host physiology and have changed along branches of the evolutionary tree, there is ongoing debate regarding whether the microbiome can evolve according to the usual evolutionary forces $(119,120)$. Nevertheless, it has been argued that focusing on functional pathways and metabolic roles of microbial communities, rather than on specific microbes, provides a better model for 
understanding evolutionary fitness (118). The co-evolution of the microbiome and human physiology may therefore be important in understanding the differences between ancient adaptive physiological survival mechanisms and modern lifestyle-related pathological responses, in women with PCOS (figure 1).

Twin studies and GWAS show that host genetics can influence the microbiome composition, and microbes can exert effects on the host genome, although the environment has an important role $(121,122)$. Humans are constantly adapting to the gut microbiome to try to determine which microorganisms are beneficial or harmful. Immune genes involved in this process are the most rapidly evolving protein-encoding genes in the mammalian genome $(123,124)$. Diversification of microbes allows humans to access dietary niches and nutritional components they otherwise wouldn't be able to access, which may be beneficial and ultimately lead to the integration of specific microbes into the ecosystem (125). Although no living population today carries an ancestral microbiome, comparison studies of non-Western and Western populations show significant differences in the relative abundances of common phyla and a much greater species diversity in nonWestern populations (126,127). A review of non-human primate and human gut microbiome datasets, revealed a changing microbiome in response to host habitat, season and diet, although there appear to be common species-specific symbiotic communities (118).

Rapid human cultural changes have resulted in significant dietary modifications in urban-industrialised communities and shifted the microbiome at an unprecedented rate. The result has been the development of a mismatch between human metabolic genes and bacteria that enhance fat storage (128). In our evolutionary past, when nutrients were scarce, it has been theorized that host selection led to the maintenance of microbes that enhance nutrient uptake or host energy storage. However, in the modern environment, where a high fat, high sugar, low fibre diet has become common and easily accessible, integration of these microbes leads to maladaptive physiological responses (40). For metabolically thrifty individuals with PCOS, harbouring microbes that enhance energy storage escalates the evolutionary conflict, furthering the development of insulin resistance and thereby progression to obesity and type 2 diabetes $(12,129)$. Further compounding this maladaptive response is the loss of microbes that are required to access other dietary niches. One example is the loss of symbiotic species of Treponema in individuals living in urban-industrialised communities (130). A change from the ancestral hunter-gatherer diet, where foods consumed changed seasonally and a wide variety of food components were eaten, to a diet that is similar across seasons and significantly less varied, is another likely contributor to reduced diversity of the microbiomes of individuals living in urbanised-industrialised communities (131).

The majority of women with PCOS are overweight or obese and evidence indicates that the microbiome of obese individuals is capable of extracting more energy from the host diet compared with the microbiome of lean individuals (132). This is thought to be driven by an expansion in pro-inflammatory species of bacteria, such as $E$. coli, and a depletion of anti-inflammatory bacteria such as Faecalibacterium prausnitzii $(133,134)$. 
Chronic low-grade 'metabolic' inflammation, or meta-inflammation, is a result of an imbalanced gut microbiome that promotes the development of insulin resistance and type 2 diabetes (135-137).

The dysbiosis of gut microbiota theory of PCOS, proposed by Tremellen in 2012, accounts for the development of all of the components of PCOS (multiple ovarian follicles, anovulation or menstrual irregularity and hyperandrogenism) (40). The theory proposes that a poor-quality diet and resulting imbalanced microbiome, induces intestinal permeability and endotoxaemia, exacerbating hyperinsulinaemia. Increased insulin levels promotes higher androgen production by the ovaries and disrupts normal follicle development. Metabolic, endocrine and environmental factors associated with PCOS are not mutually exclusive, and therefore their relative contributions to dysbiosis in PCOS remains uncertain (138). Consuming a balanced diet that is low in fat and high in fibre, can also restore balance to the ecosystem (termed eubiosis) (50). A recent study showed that dietary intake of fibre and vitamin D was significantly decreased in both lean and obese women with PCOS, compared to healthy controls, and correlated with lower diversity of the gut microbiome (139). Dysbiosis is reversible with improvement in diet quality augmented by the addition of probiotics or synbiotics $(51,56-58)$.

Dysbiosis is a consistent finding when looking at the microbiome of women with PCOS (140-143). Although most studies are small, dysbiosis has consistently been found to correlate with different physiological parameters, such as obesity, sex hormones and metabolic defects $(140,141,143)$. Similar to microbiomes associated with obesity, the microbiomes of individuals with PCOS have generally been found to have lower alpha diversity (lower numbers of bacterial taxa) than controls, and most studies describe an altered composition of taxa relative to controls $(140,143)$. However, the bacterial taxa observed to be either increased, depleted or absent in PCOS differs from study to study. This is likely due to both the immense inter-individual variation in microbiotas, as well the fact that PCOS is a quantitative trait with women having various degrees and levels of obesity and sex hormones.

In keeping with the developmental origins hypothesis previously discussed, maternal androgens may alter the composition and function of the microbiome, thereby facilitating the pathogenesis of PCOS (140). One study showed that beta diversity, which is used to measure differences between groups, was negatively correlated with hyperandrogenism, suggesting that androgens play a significant role in dysbiosis (140). The 'first hit' in utero may therefore combine with vertical transmission of a dysbiotic microbiome from a mother with PCOS, resulting in dysbiosis in the offspring. Preconception and pregnancy provide a unique opportunities for lifestyle and dietary interventions aimed at restoring eubiosis, to enable the transference of a balanced ecosystem to the offspring, via vertical transmission (118).

The accumulating scientific evidence strongly supports the significant role played by the microbiome in the pathogenesis and maintenance of PCOS, consistent with research in other related metabolic conditions. Dysbiosis is a significant factor in the pathogenesis of PCOS and an important component of a unified evolutionary model. Dysbiosis represents 
a maladaptive response of the microbiome to modern lifestyle influences and is a modifiable factor in the treatment of women with PCOS.

\subsection{Insulin Resistance}

There are a number of dilemmas when assessing the role of IR in women with PCOS. There is no consensus on the definition of IR $(144,145)$, measurement is difficult $(146,147)$, whole-body IR is usually measured although it is recognized that IR can be selective being either tissue-specific or pathway-specific within cells (148-150), normal values are categorical and determined by arbitrary cut-offs $(4.45 \mathrm{mg} / \mathrm{kg} / \mathrm{min})(144)$, testing is not recommended in clinical practice (38), reported prevalence rates in obese and lean women vary widely $(146,151)$, and the significance of IR as a pathognomonic component of PCOS is an area of debate (152-154).

Despite these limitations, it is hypothesised that IR is a significant proximate cause of PCOS and is intrinsic to the underlying pathophysiology $(44,155)$. In addition, it is recognized that IR plays a major role in the pathophysiology of all of the metabolic diseases, cardiovascular disease, some neurodegenerative diseases, and selected cancers $(22,156)$. Insulin resistance is therefore considered to be the main driver for many diseases and makes a significant contribution to the chronic disease epidemic (157). Nevertheless, being able to vary the sensitivity and physiological action of insulin is thought to have conferred a significant adaptive survival role in many animals throughout evolutionary history $(145,158)$. It has been proposed that IR may have evolved as a switch in reproductive and metabolic strategies, since the development of IR can result in anovulation and reduced fertility, in addition to differential energy repartitioning to specific tissues (158).

Insulin receptors are located on the cell membranes of most tissues in the body (159). Ligand binding to the alpha-subunit induces autophosphorylation of specific tyrosine residues on the cytoplasmic side of the membrane $(159,160)$. The activated insulin receptor initiates signal transduction via the phosphatidylinositol-3 kinase (PI-3K) metabolic pathway and the mitogen-activated protein kinase pathway (MAPK) which is involved in cell growth and proliferation (160). Insulin is an anabolic hormone that facilitates glucose removal from the blood, enhances fat storage and inhibits lipolysis in adipose tissue, stimulates glycogen synthesis in muscle and liver and inhibits hepatic glucose output (160). IR can be defined as a state where higher circulating insulin levels are necessary to achieve an integrated glucose-lowering response (145). IR results from alterations to cellular membrane insulin-receptor function or intracellular signaling, enzyme, metabolic or gene function $(145,159,160)$.

Insulin resistance can be caused by a wide variety of mechanisms that have the ability to disrupt any part of this metabolic signaling system $(53,160)$. These include autoantibodies, receptor agonists and antagonists, hormones, inflammatory cytokines, oxidative stress, nutrient sensors and metabolic intermediates (159-162). Physiological regulation of insulin function can be viewed as an adaptive mechanism to regulate the metabolic pathway of insulin signaling (PI-3K), in response to changing environmental conditions (starvation, fear, stress) $(163,164)$ or during normal alterations of internal states (pregnancy, lactation, adolescence) $(65,145,151)$. 
The physiological activation of IR allows the organism to switch from an anabolic energy storage state to a catabolic or energy mobilizing state. This allows free fatty acids to be mobilized from adipose tissue, which are then converted to glucose in the liver and released into the circulation (160). As a result of this metabolic change, blood sugar levels are maintained for vital metabolic processes and brain function (14). This adaptive protective mechanism can be pathway specific during periods of growth, such as pregnancy, lactation and adolescence, so that only the metabolic signaling (PI-3K) is inhibited and not the mitogenic pathway (MAPK), which may even be upregulated $(30,65,159)$.

When the physiology of insulin function is considered as a quantitative or continuous variable from an evolutionary perspective, it is likely that all women with PCOS, whether obese or lean, have reduced insulin sensitivity $(151,154,165)$. A systematic review and meta-analysis of euglycemic-hyperinsulinaemic clamp studies found that women with PCOS have a $27 \%$ reduction in insulin sensitivity compared to body mass index (BMI) and age-matched controls (154). In evolutionary terms, women with a PCOS metabolic phenotype would have increased survival chances during times of environmental or physiological demand for altered energy metabolism, but be more vulnerable to the pathological effects of IR when exposed to modern lifestyle factors $(14,17,158)$. In particular, a poor-quality, high glycaemic, high fat, low fibre diet has been shown to cause IR $(40,166)$. As discussed in the dysbiosis section, diet-related changes in the gastrointestinal microbiome have also been shown to cause IR in women with PCOS $(53,55)$. Numerous studies have shown that dietary modification (167-169), or treatment with probiotics or synbiotics, has the potential to restore normal insulin function $(57,170)$.

Consumption of a high glycaemic load diet results in rapid increases in blood sugar levels that cause compensatory hyperinsulinaemia $(166,171)$. Excessive dietary intake of glucose and fructose are converted to fatty acids by de novo lipogenesis in the liver, transported to adipocytes via lipoproteins, released as fatty acids to adipocytes and stored in fat globules as triglycerides (160). As a result of nutrient overload, diacylglycerol, the penultimate molecule in the synthesis of triglyceride, accumulates in the cytoplasm and binds with the threonine amino acid in the 1160 position of the insulin receptor. This inhibits autophosphorylation and down-regulates the metabolic PI-3K pathway and causes IR (160). This process has the potential to be reversible following changes in diet quantity and quality, as has been shown to occur with calorie restriction, fasting, timerestricted eating, gastric bypass surgery, low saturated fat and low glycaemic diets $(167,169,172)$. Diets high in animal protein or saturated fat can also cause IR independent of BMI $(173,174)$. These mechanisms provide the rationale for the principal recommendation of the International Guidelines, that women with PCOS should be advised about dietary modification as the first-line of management in all symptom presentations (38).

\subsection{Obesity and the lean PCOS paradox}

Insight can be obtained into the role of obesity in women with PCOS by examining the evolutionary history, genetic studies and pathological disorders of adipose tissue 
$(150,175,176)$. The ability to store energy is a basic function of life beginning with unicellular organisms (175). In multicellular organisms, from yeast to humans, the largest source of stored energy is as triglycerides in lipid droplets in order to provide energy during periods when energy demands exceed caloric intake (175). Understanding the biological functions of adipose tissue has progressed from energy storage and thermal insulation to that of a complex endocrine organ with immune and inflammatory effects and important reproductive and metabolic implications $(175,177)$.

Adipose tissue is organized into brown adipose tissue (BAT) and white adipose tissue (WAT), both with different functions (177). While the evolutionary origins of BAT and WAT are the subject of ongoing debate (175), BAT is located in the supraclavicular and thoracic prevertebral areas and is primarily involved in cold thermogenesis and regulation of basal metabolic rate (178). WAT is distributed in multiple anatomical areas such as visceral adipose tissue (VAT) and subcutaneous adipose tissue (SAT) and functions as a fat storage depot and an endocrine organ $(177,178)$. An additional layer of SAT is thought to have evolved as insulation against cool night temperatures in the Pleistocene open Savanah (179). The lower body distribution of SAT in women is hypothesised to have evolved to provide additional calorie storage for pregnancy and lactation and is unique to human females (14). Lower body SAT has a metabolic programme that makes it less readily available for every-day energy needs, but it can be mobilized during pregnancy and lactation (14). In addition, excess accumulation of SAT is much less likely to cause IR and metabolic dysfunction and explains why IR is not observed in all obese individuals $(150,180)$. Visceral WAT is associated with IR in women with PCOS leading to both metabolic and reproductive problems (181).

Multiple lines of evidence from evolutionary history, genetic and twin studies, support a genetic basis for obesity and differences in obese and lean phenotypes in women with PCOS (182-185). The majority of women with PCOS are overweight or obese, with reports ranging from 38-88\% $(151,185)$. Studies comparing obese and lean women with PCOS have a number of methodological problems including small sample size, overlap of PCOS characteristics with normal pubertal changes, non-standardized diagnostic criteria, and limited generalizability to the entire population due to a focus on a specific ethnic group $(165,181)$. In addition, most of the studies examining body composition in PCOS have relied on anthropomorphic measurements (BMI, waist circumference, waist-to-hip ratio) which are considered inaccurate compared with the current gold-standard of magnetic resonance imaging (181). Consequently, there is wide heterogeneity in reports examining the relationship between body composition measures, including extent of VAT and metabolic changes such as IR (185).

In humans, there is large individual variation in the fat storage capability and expandability of different adipose tissue depots (150). It has been hypothesised that once the genetically determined limit of expandability of SAT is reached, there is expansion of VAT and excess lipid accumulation in muscle, liver and other organs, resulting in IR, inflammation and metabolic dysregulation (150). We hypothesize that lean women with PCOS have a genetically determined limited ability to store excess lipid in SAT, but 
develop increased lipid deposition in VAT and organs such as the liver, resulting in metabolic dysregulation and IR in a similar manner to what occurs in obese women with PCOS. The wide variation in the genetic limitation of SAT expansion is also supported by studies in individuals with lipodystrophy.

Lipodystrophies are a heterogenous group of rare inherited and acquired disorders characterized by a selective loss of adipose tissue $(176,186)$. They are classified on the basis of the extent of fat loss as generalized, partial or localized (186). Patients with congenital generalised lipodystrophy have a generalized deficiency of fat from birth, usually have severe IR and develop diabetes at puberty. As a consequence of genetically limited ability for SCT lipid storage, lipids can only be stored ectopically in non-adipocytes resulting in major health consequences including IR, fatty liver, diabetes and PCOS (187). In contrast to generalised lipodystrophy, patients with familial partial lipodystrophy have normal fat distribution at birth but loose SAT in the limbs, buttocks and hips, at puberty. Fifty percent of women develop diabetes and $20-35 \%$ develop irregular periods and polycystic ovaries (176) . Despite the rare nature of these syndromes much has been learned about the underlying genetic variants involved (186).

Elucidation of clinical subtypes and the genetic background of patients with lipodystrophies may pave the way to new insights into the role of fat partitioning and obesity, and has implications for understanding the pathogenesis of insulin resistance, diabetes and PCOS (176). Lean women with PCOS may have a genetic predisposition for limited SCT fat storage, coupled with underlying metabolic predispositions, that result in deposition of excess lipid in VAT and liver and the observed metabolic features of IR, fatty liver and diabetes. If the extent of IR and ectopic fat deposition is excessive, the resulting hormonal changes may be sufficient to cause oligomenorrhoea and sub-fertility as occurs with secondary familial partial lipodystrophy type $2(187,188)$. If this underlying mechanism is confirmed in future studies, the main difference between women with lean or obese PCOS may be the combined effects of metabolic programming and the genetically-determined extent of SCT fat deposition. This would explain why lean women have all the same clinical, biochemical and endocrine features, although possibly less severe, than overweight and obese women with PCOS (185).

\subsection{Environmental chemical exposure}

Anthropomorphic chemical exposure is ubiquitous in the environment and has possible effects on many aspects related to women's health (36,189-191). Historically, many environmental chemicals have resulted in large-scale health disasters in human populations including diethylstilbesterol (DES), dichlorodiphenyltrichloroethane (DDT), asbestos, lead, mercury and nicotine (191). There over 191 million organic and inorganic chemicals registered on the Chemical Abstract Service Registry (192). Detailed analysis of risks is extremely limited and regulation relies on animal toxicology, in-vitro assays, and epidemiological studies that retrospectively examine adverse effects after population exposure $(193,194)$. More recently, toxogenetic testing of chemical-gene interactions have been employed to identify molecular pathways involved in causing toxicity (193). These 
studies have concluded that the majority of endocrine and metabolic pathways are sensitive to the effects of environmental chemicals (193).

The identification of more than 1000 EDC in food, air, water, pesticides, plastics, personal care products, and other consumer goods, raises specific concerns for pregnant women and women with increased susceptibility to metabolic diseases like PCOS $(36,171,191,195,196)$. Endocrine disrupting chemicals may be involved in the pathogenesis of PCOS given their known and potential hormonal and metabolic effects $(36,189,197)$. This includes many of the areas that have been considered in the unified evolutionary model, such as developmental epigenetic programming, microbiome composition and function, metabolic processes such IR, and regulation of body weight.

\subsubsection{EDC and DOHaD}

Many observational studies have demonstrated the presence of EDC in maternal and fetal serum and urine, amniotic fluid, cord blood and breast milk (198-200). Six classes of EDC have been shown to cross the placenta confirming that the fetus is exposed at all stages of development $(109,198)$. Although it is impossible to perform experimental studies in humans, evidence from epidemiological, molecular toxicology and animal studies provide compelling evidence of adverse developmental effects and transgenerational toxicity $(171,189,191,201,202)$. The realisation of the tragic effects of DES in the 1970's was first example of an in-utero exposure causing serious transgenerational health effects (191). This was followed by increasing interest in identifying the properties of environmental oestrogens (36).

Several oestrogenic EDC have been associated with birth outcomes that are thought to be associated with the development of PCOS (189). These include decreased birthweight (perfluoroakyl substances [PFAS], perfluorooctanoic acid) and preterm birth (di-2ethylhexyl phthalate) (201). Prenatal exposure to androgenic EDC (triclosan, glyphosate, tributyltin, nicotine) is of increasing concern, given the suspected epigenetic role of inutero androgen exposure in the pathogenesis of PCOS $(48,203,204)$. EDC can act at any stage of the human lifespan, including preconception and prenatally, and are increasingly becoming a priority in PCOS research (205).

\subsubsection{EDC and the microbiome}

As discussed above, the microbiome is increasingly considered to make a significant contribution to many human diseases, including PCOS $(40,206)$. EDC that disrupts the composition or function of the microbiome have been termed "microbiota disrupting chemicals" (207). In turn, any disruption of the microbiome from EDC can impact crucial metabolic and endocrine physiology and homeostasis $(36,208)$. A number of studies have reviewed the effect of EDC in invertebrate and vertebrate species, animal models and humans. These studies have found that BPA, phthalates, artificial sweeteners, heavy metals, fungicies, pesticides and microplastics can all affect the gut microbiome, and have metabolic and obesogenic effects $(202,209,210)$. They have concluded that EDC exert their effects in a variety of species via a range of mechanisms, including modification of 
epigenetic, cell signalling and metabolomic pathways, in addition to their effects on the microbiome.

Human exposure to the herbicide glyphosate, through diet and drinking water, has also been reported to alter gut microbial communities (211). Glyphosate-mediated inhibition of 5-enolpyruvylshikimate-3-phosphate synthase in intestinal microbiota has been shown to alter composition and enrich potentially pathogenic bacteria (212-214). In addition, microbiota exposure to glyphosate has been shown to alter mucosal-associated T-cells and promote a pro-inflammatory immune response (211). Taken together, EDC have been found to alter microbial composition and diversity $(207,213)$, disrupt gastrointestinal barrier integrity $(202,215)$, increase systemic endotoxin levels and inflammatory cytokines $(216,217)$, alter the production of metabolites and influence metabolomic patterns (210), all of which have been proposed to be involved in the pathogenesis of PCOS (40).

\subsubsection{EDC, insulin resistance and diabetes}

Kahn et al reviewed six cohort studies and 2 case-control studies that raise concerns about exposure to PFAS in pregnancy and increased risk of impaired glucose tolerance and gestational diabetes in different ethnic groups (189). They also identified 4 studies showing similar increased risk with phthalate exposure during pregnancy, and one study that did not identify an association with gestational diabetes. Animal studies have found that some EDC target alpha and beta cells in the pancreas, adipose cells and hepatocytes, and contribute to insulin resistance (218). As a result of these and many other concerning studies the Endocrine Society issued a scientific statement cautioning that emerging evidence ties EDC exposure to two of the biggest public health threats facing society, diabetes and obesity $(219,220)$.

\subsubsection{EDC and obesity}

A large number of EDC are now classified as "obesogens" due to their suspected role in promoting weight-gain and contributing to the global rise in obesity $(202,203,221)$. So far, about 50 obesogens have been recognized including tributyltin, parabins, DDT, cadmium, persistent organic pollutants and many others $(202,222,223)$. Three of the most studied compounds are BPA, phthalates and PFAS (200,201,221). Evidence from multiple birth cohort studies have shown an association between prenatal exposure to PFAS and childhood obesity $(200,201)$. A number of reports have suggested that exposure to PFAS and phthalates also contribute to weight gain in adults (224). Two trials have identified an association between weight gain (Diabetes Prevention Trial Program Lifestyle Trial) (225) and reduced resting metabolic rate (the POUNDS Lost trial) (226), with serum PFAS concentrations. In recognition of the suspected significant risk, the International Federation of Obstetrics and Gynecology (FIGO) recommended a full global phase out of PFAS (227). 


\subsubsection{EDC and PCOS}

A large number of cross-sectional studies have identified associations between EDC and PCOS, including PFAS, phthalates, bisphenol-A, triclosan and nicotine $(196,208,228,229)$. Experimental animal studies have shown that exposure to androgenic EDC in pregnancy can result in significantly increased androgen levels in female offspring $(36,48)$. Other androgenic EDC have been found to alter surrogate markers of developmental programming, such as anogenital distance (224). Although there are no specific toxicogenetic studies in women with PCOS, many EDC have been found to activate signalling pathways thought to be involved in the pathogenesis of PCOS $(193,208)$. Taken together, the available evidence suggests EDC are likely to have a role in the pathogenesis of PCOS.

\subsubsection{EDC recommendations}

There is a significant global imperative to implement a multifaceted global programme to address the effects of EDC on human health using a hazard-based approach in preference to the current risk-based regulatory framework (230). As a result, implementation of the precautionary principle is a high priority in counselling women with PCOS (231). International professional bodies (The Royal College of Obstetricians and Gynaecologists, Endocrine Society, FIGO) have recommended that all pregnant women should be advised of the possible risks of EDC and that education programmes be developed to inform health professionals $(220,232,233)$. An explanation of the pathogenesis of PCOS (discussed below), should include reference to environmental chemical exposure and open the way for more detailed discussion of specific personalised advice and lifestyle recommendations.

\subsection{Lifestyle Contributors to the Pathogenesis of PCOS}

It has been recognized that a variety of lifestyle factors contribute to the pathogenesis of PCOS for many decades $(234,235)$. As a result, a number of lifestyle factors have been investigated for their role in the pathogenesis of PCOS. These include diet, exercise, stress, sleep disturbance and exposure to environmental chemicals $(28,41,236)$. A large number of animal studies have provided experimental evidence supporting a causative role for many of these factors either individually, or in combination (44). Human research investigating causation is limited to observational and epidemiological studies, as many experimental protocols would be unethical. As a result, proving causation in humans will be extremely difficult. In addition, proving causation in evolutionary models also has a number of significant challenges $(8,9,60)$. Nevertheless, developing a unified evolutionary model based on the large number of available human and animal studies may provide a useful evidenced-based framework for counselling women and informing future research.

Despite the limitations in proving causation, recent advances in genomics, epigenetics, metabolomics, nutrigenomics, evolutionary biology, computer technology and artificial intelligence, are providing many insights into the mechanisms of how lifestyle factors impact the pathogenesis of PCOS $(9,90,235,237)$. We have attempted to integrate the research findings supporting an evolutionary model into the respective sections outlined 
in this paper. It has not been our aim to comprehensively review all aspects of the role of lifestyle in the pathogenesis of PCOS. We have tried to highlight the evolutionary aspects of how diet in particular, may impact the pathogenesis of PCOS, as components of the human diet have effects on many areas of the proposed unified evolutionary model. A large body of evidence from studies in women with PCOS, and a range of other metabolic diseases, supports the view that a Western-style high glycaemic, high saturated fat, high calorie, low nutrient-dense, and low fibre diet that contains a high proportion of processed rather than whole food, contributes to the pathogenesis of PCOS $(28,40,235)$. This is likely to be exacerbated by the additional adverse effects of multiple other lifestyle factors such as EDC, stress, circadian disruption and reduced physical activity.

The dysbiosis theory of the pathogenesis of PCOS highlights the role of a poor-quality diet in the pathogenesis of PCOS and is supported by over 30 proof-of-concept studies $(40,238)$. International Guidelines for the assessment and management of PCOS recommend lifestyle management, with diet and exercise as first-line treatment for all women with PCOS, and provide a comprehensive review of the literature (7). Nutritional studies based on diet indices, diet composition and metabolomics have identified dietary components that contribute to a healthy eating pattern $(51,237,239,240)$. Healthy diet patterns, or wholefood diets, have been found to be effective in controlling and reversing many of the symptoms and metabolic alterations associated with PCOS, and have also previously been reviewed (50). Two components of a healthy wholefood diet that appear to be important from an evolutionary perspective, in addition to the requirement for fundamental macronutrients (protein, fat and carbohydrate) and essential micronutrients (vitamins and minerals), are dietary fibre and polyphenols.

Throughout evolutionary history, humans have obtained nutrients from a wide variety of plant and animal food sources (241). These foods provided macronutrients, micronutrients and contingent nutrient factors that contain a range of bioactive components. Contingent nutrients include a variety of compounds that are not essential but may be beneficial to human health (242). Polyphenols are an important contingent nutrient, and comprise a large collection of plant-derived secondary metabolites that have been found to have beneficial biological and metabolic effects when consumed (243). Dietary polyphenols improve microbiota diversity and undergo extensive biotransformation by a variety of microbial species (244). It is estimated that less than $5 \%$ of ingested polyphenols reach the circulation intact (245). A large number of microbiallyderived polyphenol metabolites can be detected in plasma compared with low levels of the parent compounds (246). Polyphenols have potent anti-inflammatory and antioxidant effects and are the most abundant antioxidant in the human diet (246). Not surprisingly, there has been significant interest in investigating the possible beneficial effects of polyphenols in PCOS, since the pathophysiology involves oxidative stress, chronic inflammation and alterations in the microbiome (247-250).

Polyphenol-rich foods have historically made up a considerable proportion of the dietary intake in many Hunter-gatherer societies and post-agricultural communities, and until recently, in Western nations (251-253). Polyphenols are present in fruits, vegetables, 
legumes, nuts, and whole grains, as well as plant-derived foods and drinks like green tea, red wine, and chocolate (50). Women with PCOS have been noted to consume diets lower in polyphenol-containing foods (236). Consumption of polyphenols and polyphenol-rich foods and drinks have been found to improve a number of important outcome measures in women with PCOS, such as body weight, metabolic abnormalities, and serum androgen levels (50). Some polyphenols can act as selective oestrogen receptor modulators and may provide unique benefits to women with PCOS due to estrogen-related effects (254). Polyphenols are therefore an important part of a healthy diet and have been investigated for their potential role in the pathogenesis of PCOS (50). A healthy wholefood diet contains a wide variety of polyphenols coupled with the necessary dietary fibre required for optimal microbiome and metabolic function.

As previously discussed, the modern Western diet and lifestyle is at odds with our evolutionary background. In general, our traditional hunter-gatherer ancestors consumed significantly more fibre than modern populations. Studies that have investigated the dietary patterns of remaining contemporary Hunter-gatherer societies, have found their dietary fibre intake to be around 80-150 grams per day (255). This contrasts with the contemporary Western diet, where the average fibre intake is 18.2 grams per day in children and 20.7 grams per day in adults (256). Adequate dietary fibre consumption is important as it has a number of benefits, such as improved insulin sensitivity, reduced blood glucose levels, decreased systemic inflammation, lower serum levels of androgens and LPS, all of which have been linked to the pathogenesis of PCOS (257-260).

Recent systematic reviews of observational studies and randomized controlled trials have found dietary fibre consumption to be inversely related to risk of obesity, type 2 diabetes, and cardiovascular disease $(261,262)$. A recent cohort study from Canada found that obese women with PCOS consumed significantly less dietary fibre than normal weight women without PCOS (263). In addition, fibre intake of women with PCOS was negatively correlated with IR, fasting insulin, glucose tolerance and serum androgens (263). Hence, the mismatch between the amount of fibre traditionally consumed and the fibre content of Western diets, may be an important dietary component contributing to the increased rates of PCOS seen in developed and developing nations.

The current low level of fibre consumption in Western nations also contributes to a lack of microbial diversity in the microbiota. The amount and variety of fibre in the diet is one of the main determinants of ecosystem diversity (264). Lack of microbial diversity has been associated with obesity, IR, and systemic inflammation $(136,265,266)$. As previously discussed, low diversity is one of the key microbiota patterns observed in women with PCOS, and has been positively associated with hyperandrogenism, total testosterone levels, and hirsutism in this population (267). Conversely, ecosystem diversity and richness are hallmarks of Hunter-gatherer microbiotas who consume a high-fibre, more diverse plantbased diet $(255,268)$. A shift towards a more wholefood diet therefore provides a variety of phytonutrients, polyphenols and fibre, in addition to the other essential macronutrients and micronutrients, and is likely to make a significant difference to metabolic and symptomatic outcomes in women with PCOS. 
Although discussion of specific details related to lifestyle counselling are beyond the scope of this review, it is clear that improving outcomes in PCOS will require a multifaceted population-based approach that includes public health measures $(269,270)$, improved compliance-aiding strategies, inclusion of nutrition training in medical education (271), implementation of current best-practice management strategies, and further development of the International Guidelines for the Assessment and Management of PCOS (7).

\subsection{Conceptual framework of the unified evolutionary theory}

Comprehensive International Guidelines have made 166 recommendations for the assessment and management of PCOS (38). We believe the current unified evolutionary theory of the pathogenesis of PCOS provides a conceptual framework that may help practitioners and patients understand the development of PCOS symptoms and pathology in the context of our modern lifestyle and environment. It will hopefully contribute to improved communication, result in improved feelings of empowerment over the personal manifestations of PCOS, improve compliance, reduce morbidity, increase quality of life and inform future research (figure 3).

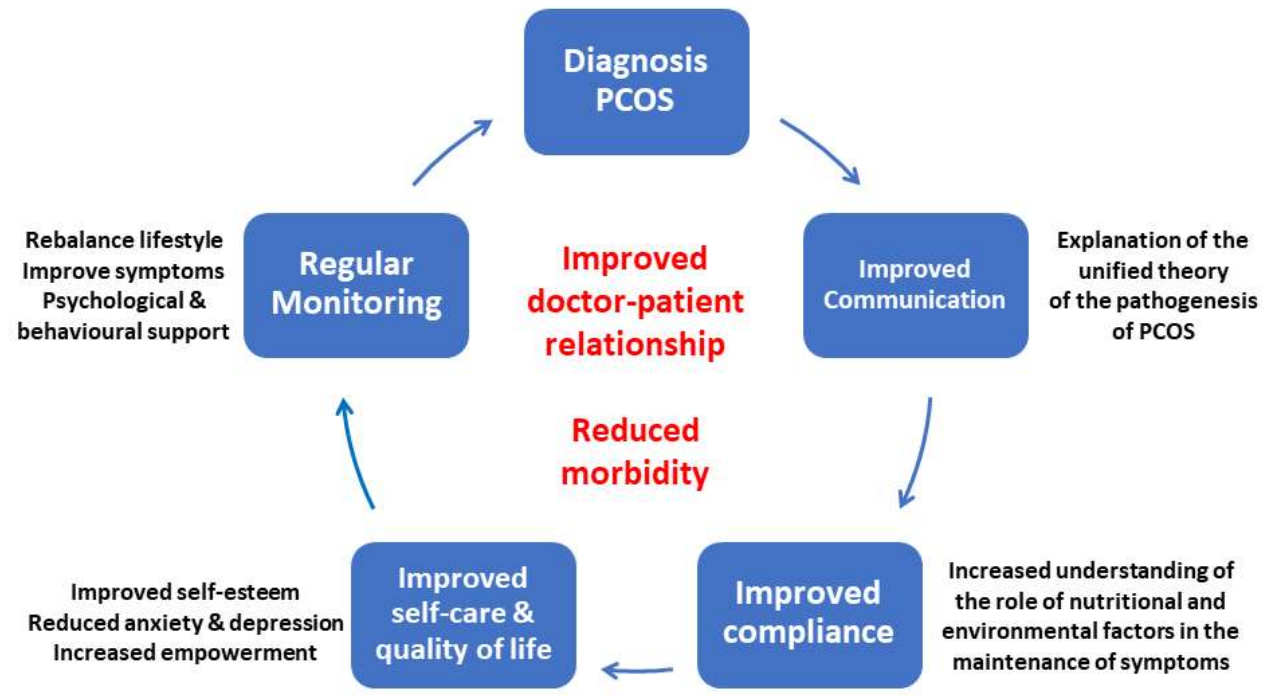

Figure 3. Impact of the unified theory on the management of polycystic ovary syndrome

\subsection{Explanation to Women Diagnosed with PCOS}

"Polycystic ovary syndrome is a problem that is inherited from both of your parents. The inherited genes are activated by a range of dietary and environmental factors that can cause a number of symptoms. These include weight gain, irregular periods, acne, excess hair growth, hair loss, anxiety and depression. Women with PCOS are also at risk of developing a range of other problems throughout their lifetime if they are not adequately treated. These include gestational diabetes, type 2 diabetes, heart disease and fertility problems. All of these symptoms and problems can be treated, controlled and reversed with appropriate lifestyle changes. These include a healthy 
diet, exercise, avoiding environmental chemicals, stress management techniques, sleep and support from friends, family and health professionals. In addition, there are a range of medical and natural treatments that can also be used. Women with PCOS can have healthy, active lives with normal fertility".

\section{Conclusions}

Substantial evidence and discussion support an evolutionary basis for the pathogenesis of polycystic ovary syndrome, although many of the mechanistic details are yet to be determined. Nevertheless, multiple lines of evidence from evolutionary theory, comparative biology, genetics, epigenetics, metabolism research, and cell biology, provide supportive evidence and hypothesis-generating data. The ability of animals to synchronize internal physiology, metabolism and reproductive function, with our changing external environment and habitat, are a necessary requirement for individual and species survival. The co-operative and sometimes competitive evolution of metabolism and reproduction provided adaptive survival mechanisms in ancestral environments that appear to be maladaptive in modern environments.

Lifestyle and environmental influences such as food abundance, altered food quality, chemical exposure, circadian disruption, chronic stress and sedentary behaviour, combine to redirect previously beneficial adaptations into adverse symptoms and disease. A unified evolutionary model provides a conceptual framework that considers the role of genetics, developmental programming, the microbiome, dysbiosis, environmental chemical exposure, metabolism, reproduction, and lifestyle factors that are involved in the initiation, treatment and prevention of PCOS. Mechanistic studies of the relative contributions of these and other ultimate and proximate causes are the subject of ongoing research and discussion. An evolutionary model therefore provides a framework to enhance practitioner and patient understanding, improve compliance with lifestyle interventions, reduce morbidity, improve quality of life and will evolve and change over time.

Author Contributions: JP conceptualized, designed and wrote the original draft of the manuscript; $\mathrm{COB}$ conceptualization, writing, reviewed and edited the manuscript; JH conceptualization, writing, reviewed and edited the manuscript; FLG conceptualized, reviewed, edited and significantly improved the manuscript. All authors critically revised the manuscript and approved the final submitted version of the manuscript.

Funding: Not applicable

Institutional Review Board Statement: Not applicable

Informed Consent Statement: Not applicable

Acknowledgments: Permission to reprint figures 1-3 were obtained from the Journal of the Australasian College of Nutritional and Environmental Medicine.

Conflicts of Interest: The authors declare no conflict of interest. 


\section{References}

1. Bodai BI, Nakata TE, Wong WT, Clark DR, Lawenda S, Tsou C, et al. Lifestyle Medicine: A Brief Review of Its Dramatic Impact on Health and Survival. Perm J. 2017;22:17-25.

2. McMacken M, Shah S. A plant-based diet for the prevention and treatment of type 2 diabetes. J Geriatr Cardiol. 2017;14(5):342-54.

3. Gakidou E, Afshin A, Abajobir AA, Abate KH, Abbafati C, Abbas KM, et al. Global, regional, and national comparative risk assessment of 84 behavioural, environmental and occupational, and metabolic risks or clusters of risks, 1990-2016: A systematic analysis for the Global Burden of Disease Study 2016. Lancet. 2017;390(10100):1345-422.

4. Parker J. NEM : A New Paradigm for Understanding the Common Origins of the Chronic Disease Epidemic. ACNEM J. 2018;37(3):6-11.

5. Glastras, SJ. Valvi, D. Bansal A. Editorial: Developmental programming of metabolic diseases. Front Endocrinol (Lausanne). 2021;12(781361):1-3.

6. Zore T, Joshi N V., Lizneva D, Azziz R. Polycystic Ovarian Syndrome: Long-Term Health Consequences. Vol. 35, Seminars in Reproductive Medicine. 2017. p. 271-81.

7. Teede H, Misso M, Costello M, Dokras A, Laven J, Moran L, et al. International evidence-based guideline for the assessment and management of polycystic ovary syndrome 2018. National Health and Medical Research Council (NHMRC). 2018. 1-198 p.

8. Benton ML. The influence of evolutionary history on human health and disease. Nat Rev Genet [Internet]. 2021; Available from: http://dx.doi.org/10.1038/s41576-020-00305-9

9. Painter D. The evolution of evolutionary medicine. In: The Dynamics of Science: Computational Frontiers in history and philosophy of science. Pittsburgh University Press; 2020.

10. Fay JC. Disease consequences of human adaptation. Appl Transl Genomics [Internet]. 2013;2(1):42-7. Available from: http://dx.doi.org/10.1016/j.atg.2013.08.001

11. Pathak G, Nichter M. Polycystic ovary syndrome in globalizing India: An ecosocial perspective on an emerging lifestyle disease. Soc Sci Med [Internet]. 2015;146(March 2017):21-8. Available from: http://dx.doi.org/10.1016/j.socscimed.2015.10.007

12. Parker J, O'Brien C. Evolutionary and genetic antecedents to the pathogenesis of polycystic ovary syndrome (PCOS). J ACNEM. 2021;40(1).

13. Stearns SC. Evolutionary medicine: Its scope, interest and potential. Proc R Soc B Biol Sci. 2012;279(1746):4305-21.

14. Tsatsoulis, A. Mantzaris, MD. Sofia, B. Andrikoula M. Insulin resistance: An adaptive mechanism becomes maladaptive in the current environment - An evolutionary perspective. Metabolism. 2012;

15. Shaw LMA, Elton S. Polycystic ovary syndrome: A transgenerational evolutionary adaptation. BJOG An Int J Obstet Gynaecol. 2008;115(2):144-8.

16. Charifson MA, Trumble BC. Evolutionary origins of polycystic ovary syndrome: An environmental mismatch disorder. Evol Med Public Heal. 2019;2019(1):50-63.

17. Azziz R, Dumesic DA, Goodarzi MO. Polycystic ovary syndrome: An ancient disorder? Fertil Steril [Internet]. 2011;95(5):1544-8. Available from: http://dx.doi.org/10.1016/j.fertnstert.2010.09.032

18. Teede, H., Deeks, H., Moran L. Polycystic ovary syndrome: A complex condition with psychological, reproductive and metabolic manifestations that impacts on health across the lifespan. BMC Med [Internet]. 2010;8. Available from: http://www.biomedcentral.com/1741-

7015/8/41\%5Cnhttp://ovidsp.ovid.com/ovidweb.cgi?T=JS\&PAGE=reference\&D=emed9\&NEWS=N\&AN=2010416064

19. Sanchez-Garrido MA, Tena-Sempere M. Metabolic dysfunction in polycystic ovary syndrome: Pathogenic role of androgen excess and potential therapeutic strategies. Mol Metab [Internet]. 2020;35(February):100937. Available from: 
https://doi.org/10.1016/j.molmet.2020.01.001

20. Glueck CJ, Goldenberg N. Characteristics of obesity in polycystic ovary syndrome: Etiology, treatment, and genetics. Metabolism [Internet]. 2019;92:108-20. Available from: https://doi.org/10.1016/j.metabol.2018.11.002

21. Reyes-Muñoz E, Castellanos-Barroso G, Ramírez-Eugenio BY, Ortega-González C, Parra A, Castillo-Mora A, et al. The risk of gestational diabetes mellitus among Mexican women with a history of infertility and polycystic ovary syndrome. Fertil Steril. 2012;97(6):1467-71.

22. Rodgers RJ, Avery JC, Moore VM, Davies MJ, Azziz R, Stener-Victorin E, et al. Complex diseases and co-morbidities: Polycystic ovary syndrome and type 2 diabetes mellitus. Endocr Connect. 2019;8(3):R71-5.

23. Wu J, Yao XY, Shi RX, Liu SF, Wang XY. A potential link between polycystic ovary syndrome and non-alcoholic fatty liver disease: An update meta-analysis. Reprod Health. 2018;15(1):1-9.

24. Yumiceba, V., Lopez-Cortes, A., Perez-Villa A. Oncology and Pharmacogenomics Insights in Polycystic Ovary Syndrome : An Integrative Analysis. Front Endocrinol (Lausanne). 2020;11(October):1-21.

25. Li G, Hu J, Zhang S, Fan W, Wen L, Wang G, et al. Changes in Resting-State Cerebral Activity in Women With Polycystic Ovary Syndrome: A Functional MR Imaging Study. Front Endocrinol (Lausanne). 2020;11(December):1-10.

26. Cooper H. Hereditary factors in the Stein leventhal 1968. Am J Obstet Gynecol. 1968;100(3):371-87.

27. Diamanti-Kandarakis E, Piperi C. Genetics of polycystic ovary syndrome: Searching for the way out of the labyrinth. Hum Reprod Update. 2005;11(6):631-43.

28. Parker J. Understanding the Pathogenesis of Polycystic Ovary Syndrome : A transgenerational evolutionary adaptation to lifestyle and the environment. ACNEM J. 2020;39(4).

29. Day F, Karaderi T, Jones MR, Meun C, He C, Drong A, et al. Large-scale genome-wide meta-analysis of polycystic ovary syndrome suggests shared genetic architecture for different diagnosis criteria. PLoS Genet. 2018;

30. Crespo RP, Bachega TASS, Mendonça BB, Gomes LG. An update of genetic basis of PCOS pathogenesis. Arch Endocrinol Metab. 2018;62(3):352-61.

31. Jones MR, Goodarzi MO. Genetic determinants of polycystic ovary syndrome: progress and future directions. Fertil Steril [Internet]. 2016;106(1):25-32. Available from: http://dx.doi.org/10.1016/j.fertnstert.2016.04.040

32. Varanasi LC, Subasinghe A, Jayasinghe YL, Callegari ET, Garland SM, Gorelik A, et al. Polycystic ovarian syndrome: Prevalence and impact on the wellbeing of Australian women aged 16-29 years. Aust New Zeal J Obstet Gynaecol. 2018;58(2):222-33.

33. Ding T, Hardiman PJ, Petersen I, Wang FF, Qu F, Baio G. The prevalence of polycystic ovary syndrome in reproductiveaged women of different ethnicity: A systematic review and meta-analysis. Oncotarget. 2017;8(56):96351-8.

34. Shao S, Zhao H, Lu Z, Lei X, Zhang Y. Circadian rhythms within the female hpg axis: From physiology to etiology. Endocrinol (United States). 2021;162(8):1-12.

35. Wang F et al. Association between circadian rhythm disruption and polycystic ovary syndrome. Fertil Steril. 2021;115(3):77181 .

36. Piazza MJ, Urbanetz AA. Environmental toxins and the impact of other endocrine disrupting chemicals in women's reproductive health. J Bras Reprod Assist. 2019;23(2):154-64.

37. Basu B, Chowdhury O, Saha S. Possible link between stress-related factors and altered body composition in women with polycystic ovarian syndrome. J Hum Reprod Sci. 2018;11(1):10-8.

38. Teede HJ, Misso ML, Costello MF, Dokras A, Laven J, Moran L, et al. Recommendations from the international evidencebased guideline for the assessment and management of polycystic ovary syndrome. Fertil Steril. 2018;110(3):364-79.

39. Casarini L, Simoni M, Brigante G. Is polycystic ovary syndrome a sexual conflict? A review. Reprod Biomed Online [Internet]. 2016;32(4):350-61. Available from: http://dx.doi.org/10.1016/j.rbmo.2016.01.011 
40. Tremellen K, Pearce K. Dysbiosis of Gut Microbiota (DOGMA) - A novel theory for the development of Polycystic Ovarian Syndrome. Med Hypotheses [Internet]. 2012;79(1):104-12. Available from: http://dx.doi.org/10.1016/j.mehy.2012.04.016

41. Parker J, O’Brien C, Gersh FL. Developmental origins and transgenerational inheritance of polycystic ovary syndrome. Aust New Zeal J Obstet Gynaecol. 2021;1-5.

42. Abbott DH, Dumesic DA, Franks S. Developmental origin of polycystic ovary syndrome - A hypothesis. J Endocrinol. 2002;174(1):1-5.

43. Rosenfield RL, Ehrmann DA. The Pathogenesis of Polycystic Ovary Syndrome (PCOS): The hypothesis of PCOS as functional ovarian hyperandrogenism revisited. Endocr Rev. 2016;37(5):467-520.

44. Stener-Victorin E, Padmanabhan V, Walters KA, Campbell RE, Benrick A, Giacobini P, et al. Animal Models to Understand the Etiology and Pathophysiology of Polycystic Ovary Syndrome. Endocr Rev. 2020;41(4):538-76.

45. Abbott DH, Dumesic DA, Abbott DH. Fetal androgen excess provides a developmental origin for polycystic ovary syndrome. Expert Rev Obs Gynecol. 2009;4(1):1-7.

46. Abbott DH, Kraynak M, Dumesic DA, Levine JE. In utero Androgen Excess: A Developmental Commonality Preceding Polycystic Ovary Syndrome? Front Horm Res. 2019;53:1-17.

47. Abbott DH, Rayome BH, Dumesic DA, Lewis KC, Edwards AK, Wallen K, et al. Clustering of PCOS-like traits in naturally hyperandrogenic female rhesus monkeys. Hum Reprod. 2017;32(4):923-36.

48. Hewlett M, Chow E, Aschengrau A, Mahalingaiah S. Prenatal Exposure to Endocrine Disruptors: A Developmental Etiology for Polycystic Ovary Syndrome. Reprod Sci. 2017;24(1):19-27.

49. Neel JV. Diabetes Mellitis: a “thrifty” genotype rendered detrimental by “progress”? Am J Hum Genet. 1962;14:353-62.

50. Parker J, Hawrelak J, Gersh FL. Nutritional role of polyphenols as a component of a wholefood diet in the management of polycystic ovary syndrome. J ACNEM. 2021;40(2).

51. Tremellen KPK. Nutrition, Fertility, and Human Reproductive Function. In: Nutrition, Fertility, and Human Reproductive Function. Adelaide: CRC Press; 2015. p. 27-50.

52. Rizk MG, Thackray VG. Intersection of Polycystic Ovary Syndrome and the Gut Microbiome. J Endocr Soc. 2021;5(2):1-16.

53. He FF, Li YM. Role of gut microbiota in the development of insulin resistance and the mechanism underlying polycystic ovary syndrome: A review. J Ovarian Res. 2020;13(1):1-13.

54. Chen F. Analysis of the gut microbial composition in polycystic ovary syndrome with acne. Zigong Matern Child Heal Hosp. 2019;35(14):2246-51.

55. Zhou L, Ni Z, Cheng W, Yu J, Sun S, Zhai D, et al. Characteristic gut microbiota and predicted metabolic functions in women with PCOS. Endocr Connect. 2020;9(1):63-73.

56. Tabrizi R, Ostadmohammadi V, Akbari M, Lankarani KB, Vakili S, Peymani P, et al. The Effects of Probiotic Supplementation on Clinical Symptom, Weight Loss, Glycemic Control, Lipid and Hormonal Profiles, Biomarkers of Inflammation, and Oxidative Stress in Women with Polycystic Ovary Syndrome: a Systematic Review and Meta-analysis of Ra. Probiotics Antimicrob Proteins. 2019;

57. Darvishi S, Rafraf M, Asghari-Jafarabadi M, Farzadi L. Synbiotic Supplementation Improves Metabolic Factors and Obesity Values in Women with Polycystic Ovary Syndrome Independent of Affecting Apelin Levels: A Randomized Double-Blind Placebo - Controlled Clinical Trial. Int J Fertil Steril. 2021;15(1):51-9.

58. Karimi E, Moini A, Yaseri M, Shirzad N, Sepidarkish M, Hossein-Boroujerdi M, et al. Effects of synbiotic supplementation on metabolic parameters and apelin in women with polycystic ovary syndrome: A randomised double-blind placebocontrolled trial. Br J Nutr. 2018;119(4):398-406.

59. Stein IF, Leventhal ML. Amenorrhea associated with bilateral polycystic ovaries. Am J Obstet Gynecol. 1935;29(2):181-91.

60. Corbett S, Morin-Papunen L. The Polycystic Ovary Syndrome and recent human evolution. Mol Cell Endocrinol [Internet]. 
2013;373(1-2):39-50. Available from: http://dx.doi.org/10.1016/j.mce.2013.01.001

61. Rodgers RJ, Suturina L, Lizneva D, Davies MJ, Hummitzsch K, Irving-Rodgers HF, et al. Is polycystic ovary syndrome a 20th Century phenomenon? Med Hypotheses. 2019;124(November 2018):31-4.

62. Holte J. Polycystic ovary syndrome and insulin resistance: Thrifty genes struggling with over-feeding and sedentary life style? J Endocrinol Invest. 1998;21(9):589-601.

63. Corbett SJ, McMichael AJ, Prentice AM. Type 2 diabetes, cardiovascular disease, and the evolutionary paradox of the polycystic ovary syndrome: A fertility first hypothesis. Am J Hum Biol. 2009;21(5):587-98.

64. Dinsdale NL, Crespi BJ. Endometriosis and polycystic ovary syndrome are diametric disorders. Evol Appl. 2021;14(7):1693715 .

65. Sonagra AD. Normal Pregnancy- A State of Insulin Resistance. J Clin Diagnostic Res. 2014;3-5.

66. Lipovka Y, Chen H, Vagner J, Price TJ, Tsao TS, Konhilas JP. Oestrogen receptors interact with the $\alpha$-catalytic subunit of AMP-activated protein kinase. Biosci Rep. 2015;35(5).

67. López M, Tena-Sempere M. Estradiol effects on hypothalamic AMPK and BAT thermogenesis: A gateway for obesity treatment? Pharmacol Ther. 2017;178:109-22.

68. Rettberg JR, Yao J, Brinton RD. Estrogen: A master regulator of bioenergetic systems in the brain and body. Front Neuroendocrinol. 2014;35(1):8-30.

69. Alaaraj N, Soliman A, Hamed N, Alyafei F, De Sanctis V. Understanding the complex role of mtorc as an intracellular critical mediator of whole-body metabolism in anorexia nervosa: A mini review. Acta Biomed. 2021;92(1):1-11.

70. Seif MW, Diamond K, Nickkho-Amiry M. Obesity and menstrual disorders. Best Pract Res Clin Obstet Gynaecol [Internet]. 2015;29(4):516-27. Available from: http://dx.doi.org/10.1016/j.bpobgyn.2014.10.010

71. Draper CF, Duisters K, Weger B, Chakrabarti A, Harms AC, Brennan L, et al. Menstrual cycle rhythmicity: metabolic patterns in healthy women. Sci Rep [Internet]. 2018;8(1):1-15. Available from: http://dx.doi.org/10.1038/s41598-018-32647-0

72. Roh E, Song DK, Kim MS. Emerging role of the brain in the homeostatic regulation of energy and glucose metabolism. Exp Mol Med [Internet]. 2016;48(3):e216-12. Available from: http://dx.doi.org/10.1038/emm.2016.4

73. Ong Q, Han W, Yang X. O-GlcNAc as an integrator of signaling pathways. Front Endocrinol (Lausanne). 2018;9(OCT):1-9.

74. Gnocchi D, Bruscalupi G. Circadian rhythms and hormonal homeostasis: Pathophysiological implications. Biology (Basel). 2017;6(1):1-20.

75. Ludwig DS, Aronne LJ, Astrup A, de Cabo R, Cantley LC, Friedman MI, et al. The carbohydrate-insulin model: a physiological perspective on the obesity pandemic. Am J Clin Nutr. 2021;1-13.

76. Gluckman PD, Hanson MA. Developmental and epigenetic pathways to obesity: An evolutionary-developmental perspective. Int J Obes. 2008;32:S62-71.

77. Balakumar P, Maung-U K, Jagadeesh G. Prevalence and prevention of cardiovascular disease and diabetes mellitus. Pharmacol Res [Internet]. 2016;113:600-9. Available from: http://dx.doi.org/10.1016/j.phrs.2016.09.040

78. Cooper HE, Spellacy WN, Prem KA, Cohen WD. Hereditary factors in the Stein-Leventhal syndrome. Am J Obstet Gynecol [Internet]. 1968;100(3):371-87. Available from: http://dx.doi.org/10.1016/S0002-9378(15)33704-2

79. Vink JM, Sadrzadeh S, Lambalk CB, Boomsma DI. Heritability of polycystic ovary syndrome in a Dutch twin-family study. J Clin Endocrinol Metab. 2006;91(6):2100-4.

80. Kahsar-Miller MD, Nixon C, Boots LR, Go RC, Azziz R. Prevalence of polycystic ovary syndrome (PCOS) in first-degree relatives of patients with PCOS. Fertil Steril. 2001;75(1):53-8.

81. Dunaif A. Perspectives in polycystic ovary syndrome: From hair to eternity. J Clin Endocrinol Metab. 2016;101(3):759-68.

82. Kosova G, Urbanek M. Genetics of the polycystic ovary syndrome. Mol Cell Endocrinol [Internet]. 2013;373(1-2):29-38. Available from: http://dx.doi.org/10.1016/j.mce.2012.10.009 
83. Legro RS, Driscoll D, Strauss JF, Fox J, Dunaif A. Evidence for a genetic basis for hyperandrogenemia in polycystic ovary syndrome. Proc Natl Acad Sci U S A. 1998;95(25):14956-60.

84. Lander ES, Linton LM, Birren B, Nusbaum C, Zody MC, Baldwin J, et al. Erratum: Initial sequencing and analysis of the human genome: International Human Genome Sequencing Consortium (Nature (2001) 409 (860-921)). Nature. 2001;412(6846):565-6.

85. Belmont JW, Boudreau A, Leal SM, Hardenbol P, Pasternak S, Wheeler DA, et al. A haplotype map of the human genome. Nature. 2005;437(7063):1299-320.

86. Welt CK. Genetics of Polycystic Ovary Syndrome: What is New? Endocrinol Metab Clin North Am [Internet]. 2021;50(1):7182. Available from: https://doi.org/10.1016/j.ecl.2020.10.006

87. Chen ZJ, Zhao H, He L, Shi Y, Qin Y, Shi Y, et al. Genome-wide association study identifies susceptibility loci for polycystic ovary syndrome on chromosome 2p16.3, 2p21 and 9q33.3. Nat Genet. 2011;43(1):55-9.

88. Hayes MG, Urbanek M, Ehrmann DA, Armstrong LL, Lee JY, Sisk R, et al. Genome-wide association of polycystic ovary syndrome implicates alterations in gonadotropin secretion in European ancestry populations. Nat Commun. 2015;6(May 2015).

89. Zhang Y, Ho K, Keaton JM, Hartzel DN, Day F, Justice AE, et al. A genome-wide association study of polycystic ovary syndrome identified from electronic health records. Am J Obstet Gynecol [Internet]. 2020;223(4):559.e1-559.e21. Available from: https://doi.org/10.1016/j.ajog.2020.04.004

90. Zhu, Tiantian. Goodarzi M. Causes and consequences of polycystic ovary syndrome: Insights from Mendelian Randomization. J Clin Endocrinol Metab. epub ahead.

91. Sun Q, Gao Y, Yang J, Lu J, Feng W, Yang W. Mendelian Randomization Analysis Identified Potential Genes Pleiotropically Associated with Polycystic Ovary Syndrome. Reprod Sci [Internet]. 2021; Available from: https://doi.org/10.1007/s43032-02100776-z

92. Visscher PM, Brown MA, McCarthy MI, Yang J. Five years of GWAS discovery. Am J Hum Genet [Internet]. 2012;90(1):7-24. Available from: http://dx.doi.org/10.1016/j.ajhg.2011.11.029

93. Zhu Z, Zhang F, Hu H, Bakshi A, Robinson MR, Powell JE, et al. Integration of summary data from GWAS and eQTL studies predicts complex trait gene targets. Nat Genet. 2016;48(5):481-7.

94. Rung J, Cauchi S, Albrechtsen A, Shen L, Rocheleau G, Cavalcanti-Proença C, et al. Genetic variant near IRS1 is associated with type 2 diabetes, insulin resistance and hyperinsulinemia. Nat Genet. 2009;41(10):1110-5.

95. Udler MS, McCarthy MI, Florez JC, Mahajan A. Genetic Risk Scores for Diabetes Diagnosis and Precision Medicine. Endocr Rev. 2019;40(6):1500-20.

96. Khera A V., Chaffin M, Wade KH, Zahid S, Brancale J, Xia R, et al. Polygenic Prediction of Weight and Obesity Trajectories from Birth to Adulthood. Cell [Internet]. 2019;177(3):587-596.e9. Available from: https://doi.org/10.1016/j.cell.2019.03.028

97. Plomin R, Haworth CMA, Davis OSP. Common disorders are quantitative traits. Nat Rev Genet [Internet]. 2009;10(12):8728. Available from: http://dx.doi.org/10.1038/nrg2670

98. Dumesic DA, Hoyos LR, Chazenbalk GD, Naik R, Padmanabhan V, Abbott DH. mechanisms of intergenerational transmission of ovary syndrome. Reproduction. 2020;159:1-13.

99. Sloboda DM, Hickey M, Hart R. Reproduction in females: The role of the early life environment. Hum Reprod Update. 2011;17(2):210-27.

100. Xu R, Li C, Liu X, Gao S. Insights into epigenetic patterns in mammalian early embryos. Protein Cell [Internet]. 2021;12(1):728. Available from: https://doi.org/10.1007/s13238-020-00757-z

101. Glastras SJ, Chen H, Pollock CA, Saad S. Maternal obesity increases the risk of metabolic disease and impacts renal health in offspring. Biosci Rep. 2018;38(2):1-15. 
102. Simeoni U, Armengaud JB, Siddeek B, Tolsa JF. Perinatal Origins of Adult Disease. Neonatology. 2018;113(4):393-9.

103. Risnes K, Bilsteen JF, Brown P, Pulakka A, Andersen AMN, Opdahl S, et al. Mortality Among Young Adults Born Preterm and Early Term in 4 Nordic Nations. JAMA Netw open. 2021;4(1):e2032779.

104. Behere R V., Deshmukh AS, Otiv S, Gupte MD, Yajnik CS. Maternal Vitamin B12 Status During Pregnancy and Its Association With Outcomes of Pregnancy and Health of the Offspring: A Systematic Review and Implications for Policy in India. Front Endocrinol (Lausanne). 2021;12(April):1-18.

105. Azziz R. Animal models of pcos not the real thing. Nat Rev Endocrinol2. 2017;13(7):382-4.

106. Poon K. Behavioral Feeding Circuit: Dietary Fat-Induced Effects of Inflammatory Mediators in the Hypothalamus. Front Endocrinol (Lausanne). 2020;11(November):1-12.

107. Bateson P, Gluckman P, Hanson M. The biology of developmental plasticity and the Predictive Adaptive Response hypothesis. J Physiol. 2014;592(11):2357-68.

108. Catalano PM, Presley L, Minium J, Mouzon SH De. Fetuses of obese mothers develop insulin resistance in utero. Diabetes Care. 2009;32(6):1076-80.

109. Rosenfeld CS. Transcriptomics and Other Omics Approaches to Investigate Effects of Xenobiotics on the Placenta. Front Cell Dev Biol. 2021;9(September):1-13.

110. De Melo AS, Dias SV, De Carvalho Cavalli R, Cardoso VC, Bettiol H, Barbieri MA, et al. Pathogenesis of polycystic ovary syndrome: Multifactorial assessment from the foetal stage to menopause. Reproduction. 2015;150(1):R11-24.

111. Schulz LC. The Dutch hunger winter and the developmental origins of health and disease. Proc Natl Acad Sci U S A. 2010;107(39):16757-8.

112. Gaillard R. Maternal obesity during pregnancy and cardiovascular development and disease in the offspring. Eur J Epidemiol. 2015;30(11):1141-52.

113. Ishimwe JA. Maternal microbiome in preeclampsia pathophysiology and implications on offspring health. Physiol Rep. 2021;9(10):1-19.

114. Gilbert JA, Blaser MJ, Caporaso JG, Jansson JK, Lynch S V., Knight R. Current understanding of the human microbiome. Nat Med. 2018;24(4):392-400.

115. Valdes AM, Walter J, Segal E, Spector TD. Role of the gut microbiota in nutrition and health. BMJ. 2018;361:36-44.

116. Rinninella E, Raoul P, Cintoni M, Franceschi F, Miggiano GAD, Gasbarrini A, et al. What is the healthy gut microbiota composition? A changing ecosystem across age, environment, diet, and diseases. Microorganisms. 2019;7(1).

117. Schmidt TSB, Raes J, Bork P. The Human Gut Microbiome: From Association to Modulation. Cell [Internet]. 2018;172(6):1198215. Available from: https://doi.org/10.1016/j.cell.2018.02.044

118. Davenport ER, Sanders JG, Song SJ, Amato KR, Clark AG, Knight R. The human microbiome in evolution. BMC Biol. 2017;15(1):1-12.

119. Theis KR, Dheilly NM, Klassen JL, Brucker RM, Baines JF, Bosch TCG, et al. Getting the Hologenome Concept Right: an EcoEvolutionary Framework for Hosts and Their Microbiomes. mSystems. 2016;1(2).

120. Douglas AE, Werren JH. Holes in the hologenome: Why host-microbe symbioses are not holobionts. MBio. 2016;7(2).

121. Goodrich JK, Davenport ER, Beaumont M, Jackson MA, Knight R, Ober C, et al. Genetic Determinants of the Gut Microbiome in UK Twins. Cell Host Microbe [Internet]. 2016;19(5):731-43. Available from: http://dx.doi.org/10.1016/j.chom.2016.04.017

122. Wang J, Thingholm LB, Skiecevičie J, Rausch P, Kummen M, Hov JR, et al. Genome-wide association analysis identifies variation in Vitamin D receptor and other host factors influencing the gut microbiota. Nat Genet. 2016;48(11):1396-406.

123. Liston A, Humblet-Baron S, Duffy D, Goris A. Human immune diversity: from evolution to modernity. Nat Immunol [Internet]. 2021/11/20. 2021; Available from: https://www.ncbi.nlm.nih.gov/pubmed/34795445

124. Meyerson NR, Sawyer SL. Two-stepping through time: mammals and viruses. Trends Microbiol [Internet]. 2011/05/03. 
2011;19(6):286-94. Available from: https://www.ncbi.nlm.nih.gov/pubmed/21531564

125. Greene LK, Williams C V, Junge RE, Mahefarisoa KL, Rajaonarivelo T, Rakotondrainibe H, et al. A role for gut microbiota in host niche differentiation. ISME J [Internet]. 2020/04/03. 2020;14(7):1675-87. Available from: https://www.ncbi.nlm.nih.gov/pubmed/32238913

126. Schnorr SL, Candela M, Rampelli S, Centanni M, Consolandi C, Basaglia G, et al. Gut microbiome of the Hadza huntergatherers. Nat Commun. 2014;5.

127. Clemente JC, Pehrsson EC, Blaser MJ, Sandhu K, Gao Z, Wang B, et al. The microbiome of uncontacted Amerindians. Sci Adv. 2015;1(3).

128. Shen J, Obin MS, Zhao L. The gut microbiota, obesity and insulin resistance. Mol Aspects Med [Internet]. 2013;34(1):39-58. Available from: http://dx.doi.org/10.1016/j.mam.2012.11.001

129. Zhao X, Jiang Y, Xi H, Chen L, Feng X. Exploration of the Relationship between Gut Microbiota and Polycystic Ovary Syndrome (PCOS): A Review. Geburtshilfe Frauenheilkd. 2020;80(2):161-71.

130. Obregon-Tito AJ, Tito RY, Metcalf J, Sankaranarayanan K, Clemente JC, Ursell LK, et al. Subsistence strategies in traditional societies distinguish gut microbiomes. Nat Commun [Internet]. 2015/03/26. 2015;6:6505. Available from: https://www.ncbi.nlm.nih.gov/pubmed/25807110

131. Smits SA, Leach J, Sonnenburg ED, Gonzalez CG, Lichtman JS, Reid G, et al. Seasonal cycling in the gut microbiome of the Hadza hunter-gatherers of Tanzania. Science (80- ) [Internet]. 2017/08/26. 2017;357(6353):802-6. Available from: https://www.ncbi.nlm.nih.gov/pubmed/28839072

132. Kallus SJ, Brandt LJ. The intestinal microbiota and obesity. J Clin Gastroenterol [Internet]. 2011/11/09. 2012;46(1):16-24. Available from: https:/www.ncbi.nlm.nih.gov/pubmed/22064556

133. Ridaura VK, Faith JJ, Rey FE, Cheng J, Duncan AE, Kau AL, et al. Gut microbiota from twins discordant for obesity modulate metabolism in mice. Science (80- ) [Internet]. 2013/09/07. 2013;341(6150):1241214. Available from: https://www.ncbi.nlm.nih.gov/pubmed/24009397

134. Backhed F, Ding H, Wang T, Hooper L V, Koh GY, Nagy A, et al. The gut microbiota as an environmental factor that regulates fat storage. Proc Natl Acad Sci U S A [Internet]. 2004/10/27. 2004;101(44):15718-23. Available from: https://www.ncbi.nlm.nih.gov/pubmed/15505215

135. Karlsson FH, Tremaroli V, Nookaew I, Bergstrom G, Behre CJ, Fagerberg B, et al. Gut metagenome in European women with normal, impaired and diabetic glucose control. Nature [Internet]. 2013/05/31. 2013;498(7452):99-103. Available from: https://www.ncbi.nlm.nih.gov/pubmed/23719380

136. Chatelier E Le, Nielsen T, Qin J, Prifti E, Hildebrand F, Falony G, et al. Richness of human gut microbiome correlates with metabolic markers. Nature [Internet]. 2013/08/30. 2013;500(7464):541-6. Available from: https://www.ncbi.nlm.nih.gov/pubmed/23985870

137. Qin J, Li Y, Cai Z, Li S, Zhu J, Zhang F, et al. A metagenome-wide association study of gut microbiota in type 2 diabetes. Nature [Internet]. 2012/10/02. 2012;490(7418):55-60. Available from: https://www.ncbi.nlm.nih.gov/pubmed/23023125

138. Rocha, AL. Oliveira, FL. Azevedo R. Recent advances in the understanding and management of polycystic ovary syndrome. F1000Research. 2019;8(565):1-11.

139. Liang Z, Di N, Li L, Yang D. Gut microbiota alterations reveal potential gut-brain axis changes in polycystic ovary syndrome. J Endocrinol Invest. 2021;44(8):1727-37.

140. Torres PJ, Siakowska M, Banaszewska B, Pawelczyk L, Duleba AJ, Kelley ST, et al. Gut Microbial Diversity in Women with Polycystic Ovary Syndrome Correlates with Hyperandrogenism. J Clin Endocrinol Metab. 2018;103(4):1502-11.

141. Insenser M, Murri M, Del Campo R, Martínez-García MÁ, Fernández-Durán E, Escobar-Morreale HF. Gut microbiota and the polycystic ovary syndrome: Influence of sex, sex hormones, and obesity. J Clin Endocrinol Metab. 2018;103(7):2552-62. 
142. Zhu X, Li Y, Jiang Y, Zhang J, Duan R, Liu L, et al. Prediction of Gut Microbial Community Structure and Function in Polycystic Ovary Syndrome With High Low-Density Lipoprotein Cholesterol. Front Cell Infect Microbiol [Internet]. 2021/08/06. 2021;11:665406. Available from: https://www.ncbi.nlm.nih.gov/pubmed/34350129

143. Lindheim L, Bashir M, Münzker J, Trummer C, Zachhuber V, Leber B, et al. Alterations in gut microbiome composition and barrier function are associated with reproductive and metabolic defects in women with polycystic ovary syndrome (PCOS): A pilot study. PLoS One. 2017;12(1):1-20.

144. Tam CS, Xie W, Johnson WD, Cefalu WT, Redman LM, Ravussin E. Defining insulin resistance from hyperinsulinemiceuglycemic clamps. Diabetes Care. 2012;35(7):1605-10.

145. Nolan CJ, Prentki M. Insulin resistance and insulin hypersecretion in the metabolic syndrome and type 2 diabetes: Time for a conceptual framework shift. Diabetes Vasc Dis Res [Internet]. 2019;16(2):118-27. Available from: https://doi.org/10.1177/1479164119827611

146. Diamanti-Kandarakis E, Kouli C, Alexandraki K, Spina G. Failure of mathematical indices to accurately assess insulin resistance in lean, overweight, or obese women with polycystic ovary syndrome. J Clin Endocrinol Metab. 2004;89(3):12736.

147. Singh B. Surrogate markers of insulin resistance: A review. World J Diabetes. 2010;1(2):36.

148. Wu XK, Zhou SY, Liu JX, Pöllänen P, Sallinen K, Mäkinen M, et al. Selective ovary resistance to insulin signaling in women with polycystic ovary syndrome. Fertil Steril. 2003;80(4):954-65.

149. Brown MS, Goldstein JL. Selective versus Total Insulin Resistance: A Pathogenic Paradox. Cell Metab. 2008;7(2):95-6.

150. Hardy OT, Czech MP, Corvera S. What causes the insulin resistance underlying obesity? Curr Opin Endocrinol Diabetes Obes. 2012;19(2):81-7.

151. Toosy S, Sodi R, Pappachan JM. Lean polycystic ovary syndrome (PCOS): an evidence-based practical approach. J Diabetes Metab Disord. 2018;17(2):277-85.

152. Wang J, Wu D, Guo H, Li M. Hyperandrogenemia and insulin resistance: The chief culprit of polycystic ovary syndrome. Life Sci. 2019;236(October).

153. Cibula D. Is insulin resistance an essential component of PCOS? The influence of confounding factors. Hum Reprod. 2004;19(4):757-9.

154. Cassar S, Misso ML, Hopkins WG, Shaw CS, Teede HJ, Stepto NK. Insulin resistance in polycystic ovary syndrome: A systematic review and meta-analysis of euglycaemic-hyperinsulinaemic clamp studies. Hum Reprod. 2016;31(11):2619-31.

155. Stepto NK, Cassar S, Joham AE, Hutchison SK, Harrison CL, Goldstein RF, et al. Women with polycystic ovary syndrome have intrinsic insulin resistance on euglycaemic-hyperinsulaemic clamp. Hum Reprod. 2013;28(3):777-84.

156. Rubin KH, Glintborg D, Nybo M, Abrahamsen B, Andersen M. Development and risk factors of type 2 diabetes in a nationwide population of women with polycystic ovary syndrome. J Clin Endocrinol Metab. 2017;102(10):3848-57.

157. Crofts CAP. Hyperinsulinemia: A unifying theory of chronic disease? Diabesity. 2015;1(4):34.

158. Watve MG, Yajnik CS. Evolutionary origins of insulin resistance: A behavioral switch hypothesis. BMC Evol Biol. 2007;7:113.

159. Khalid M, Alkaabi J, Khan MAB, Adem A. Insulin signal transduction perturbations in insulin resistance. Int J Mol Sci. 2021;22(16):1-17.

160. Petersen MC, Shulman GI. Mechanisms of insulin action and insulin resistance. Physiol Rev. 2018;98(4):2133-223.

161. da Silva Rosa SC, Nayak N, Caymo AM, Gordon JW. Mechanisms of muscle insulin resistance and the cross-talk with liver and adipose tissue. Physiol Rep. 2020;8(19):1-24.

162. Schenk S, Saberi M, Olefsky JM. Insulin sensitivity: Modulation by nutrients and inflammation. J Clin Invest. 2008;118(9):2992-3002. 
163. Soeters MR, Soeters PB, Schooneman MG, Houten SM, Romijn JA. Adaptive reciprocity of lipid and glucose metabolism in human short-term starvation. Am J Physiol - Endocrinol Metab. 2012;303(12):1397-407.

164. Li L, Li X, Zhou W, Messina JL. Acute psychological stress results in the rapid development of insulin resistance. J Endocrinol. 2013;217(2):175-84.

165. Morciano A, Romani F, Sagnella F, Scarinci E, Palla C, Moro F, et al. Assessment of insulin resistance in lean women with polycystic ovary syndrome. Fertil Steril [Internet]. 2014;102(1):250-256.e3. Available from: http://dx.doi.org/10.1016/j.fertnstert.2014.04.004

166. Small L, Brandon AE, Turner N, Cooney GJ. Modeling insulin resistance in rodents by alterations in diet: What have highfat and high-calorie diets revealed? Am J Physiol - Endocrinol Metab. 2018;314(3):E251-65.

167. Hallberg SJ, Gershuni VM, Hazbun TL. Reversing Type 2 Diabetes : A Narrative Review of the Evidence. 2019;

168. Rabbani, N. Xue, M. Weickert, M. Thornally P. Reversal of Insulin Resistance in Overweight and Obese Subjects by trans Resveratrol and Hesperetin Combination-Link to Dysglycemia, Blood Pressure, Dyslipidemia, and Low-Grade Inflammation. Nutrients. 2021;13(2374):1-13.

169. Shang Y, Zhou H, Hu M, Feng H. Effect of diet on insulin resistance in polycystic ovary syndrome. J Clin Endocrinol Metab. 2020;105(10):1-15.

170. Kazemi A, Soltani S, Ghorabi S, Keshtkar A, Daneshzad E, Nasri F, et al. Effect of probiotic and synbiotic supplementation on inflammatory markers in health and disease status: A systematic review and meta-analysis of clinical trials. Clin Nutr [Internet]. 2020;39(3):789-819. Available from: https://doi.org/10.1016/j.clnu.2019.04.004

171. Street ME, Bernasconi S. Endocrine-disrupting chemicals in human fetal growth. Int J Mol Sci. 2020;21(4).

172. Patterson RE, Laughlin GA, LaCroix AZ, Hartman SJ, Natarajan L, Senger CM, et al. Intermittent Fasting and Human Metabolic Health. J Acad Nutr Diet [Internet]. 2015;115(8):1203-12. Available from: http://dx.doi.org/10.1016/j.jand.2015.02.018

173. Adeva-Andany MM, González-Lucán M, Fernández-Fernández C, Carneiro-Freire N, Seco-Filgueira M, Pedre-Piñeiro AM. Effect of diet composition on insulin sensitivity in humans. Clin Nutr ESPEN. 2019;33:29-38.

174. González F, Considine R V., Abdelhadi OA, Xue J, Acton AJ. Saturated fat ingestion stimulates proatherogenic inflammation in polycystic ovary syndrome. Am J Physiol Metab. 2021;321(5):E689-701.

175. Ottaviani E, Malagoli D, Franceschi C. The evolution of the adipose tissue: A neglected enigma. Gen Comp Endocrinol [Internet]. 2011;174(1):1-4. Available from: http://dx.doi.org/10.1016/j.ygcen.2011.06.018

176. Knebel B, Müller-Wieland D, Kotzka J. Lipodystrophies-disorders of the fatty tissue. Int J Mol Sci. 2020;21(22):1-15.

177. Scheja L, Heeren J. The endocrine function of adipose tissues in health and cardiometabolic disease. Nat Rev Endocrinol [Internet]. 2019;15(9):507-24. Available from: http://dx.doi.org/10.1038/s41574-019-0230-6

178. Choe SS, Huh JY, Hwang IJ, Kim JI, Kim JB. Adipose tissue remodeling: Its role in energy metabolism and metabolic disorders. Front Endocrinol (Lausanne). 2016;7(APR):1-16.

179. Pawłowski B, Żelaźniewicz A. The evolution of perennially enlarged breasts in women: a critical review and a novel hypothesis. Biol Rev. 2021;2798:2794-809.

180. McLaughlin T, Lamendola C, Liu A, Abbasi F. Preferential fat deposition in subcutaneous versus visceral depots is associated with insulin sensitivity. J Clin Endocrinol Metab. 2011;96(11):1756-60.

181. Barrea L, Frias-Toral E, Verde L, Ceriani F, Cucalón G, Garcia-Velasquez E, et al. PCOS and nutritional approaches: Differences between lean and obese phenotype. Metab Open. 2021;12:100123.

182. Sellayah D. The impact of early human migration on brown adipose tissue evolution and its relevance to the modern obesity pandemic. J Endocr Soc. 2019;3(2):372-86.

183. Locke AE, Kahali B, Berndt SI, Justice AE, Pers TH, Day FR, et al. Genetic studies of body mass index yield new insights for 
obesity biology. Nature. 2015;518(7538):197-206.

184. Bouchard, C. Tremblay, A. Despres J et al. The response to long-term overfeeding in identical twins. N Engl J Med. 1990;322:1477-82.

185. Barber TM, Hanson P, Weickert MO, Franks S. Obesity and Polycystic Ovary Syndrome: Implications for Pathogenesis and Novel Management Strategies. Clin Med Insights Reprod Heal. 2019;13:117955811987404.

186. Hussain I, Garg A. Lipodystrophy Syndromes. Endocrinol Metab Clin North Am [Internet]. 2016;45(4):783-97. Available from: http://dx.doi.org/10.1016/j.ecl.2016.06.012

187. Gambineri A, Zanotti L. Polycystic ovary syndrome in familial partial lipodystrophy type 2 (Fpld2): Basic and clinical aspects. Nucleus [Internet]. 2018;9(1):392-7. Available from: https://doi.org/10.1080/19491034.2018.1509659

188. Garg A. Gender differences in the prevalence of metabolic complications in familial partial lipodystrophy (Dunnigan variety). J Clin Endocrinol Metab. 2000;85(5):1776-82.

189. Kahn LG, Philippat C, Nakayama SF, Slama R, Trasande L. Endocrine-disrupting chemicals: implications for human health. Lancet Diabetes Endocrinol. 2020;8(8):703-18.

190. Whitmee S, Haines A, Beyrer C, Boltz F, Capon AG, De Souza Dias BF, et al. Safeguarding human health in the Anthropocene epoch: Report of the Rockefeller Foundation-Lancet Commission on planetary health. Lancet [Internet]. 2015;386(10007):1973-2028. Available from: http://dx.doi.org/10.1016/S0140-6736(15)60901-1

191. Schug TT, Johnson AF, Birnbaum LS, Colborn T, Guillette LJ, Crews DP, et al. Minireview: Endocrine disruptors: Past lessons and future directions. Mol Endocrinol. 2016;30(8):833-47.

192. Chemical Abstract Service Registry. Available online: https://www.cas.org/cas-data/cas-registry (accessed 17 November 2021).

193. Suvorov A, Salemme V, McGaunn J, Poluyanoff A, Teffera M, Amir S. Unbiased approach for the identification of molecular mechanisms sensitive to chemical exposures. Chemosphere [Internet]. 2021;262:128362. Available from: https://doi.org/10.1016/j.chemosphere.2020.128362

194. Crinnion WJ. The CDC fourth national report on human exposure to environmental chemicals: What it tells us about our toxic burden and how it assists environmental medicine physicians. Altern Med Rev. 2010;15(2):101-8.

195. TEDX List of Potential Endocrine Disruptors. The Endocrine Disruptor Exchange. 2018.

196. Eskenazi B, Chevrier J, Rauch SA, Kogut K, Harley KG, Johnson C, et al. In utero and childhood polybrominated diphenyl ether (PBDE) exposures and neurodevelopment in the CHAMACOS study. Environ Health Perspect. 2013;121(2):257-62.

197. Parker J. Glyphosate induced intestinal permeability in the pathogenesis of PCOS. ACNEM J. 2015;34(2):3-7.

198. Mitro SD, Johnson T, Zota AR. Cumulative Chemical Exposures During Pregnancy and Early Development. Curr Environ Heal reports. 2015;2(4):367-78.

199. Barr DB, Bishop A, Needham LL. Concentrations of xenobiotic chemicals in the maternal-fetal unit. Vol. 23, Reproductive Toxicology. 2007. p. 260-6.

200. Starling AP, Adgate JL, Hamman RF, Kechris K, Calafat AM, Ye X, et al. Perfluoroalkyl substances during pregnancy and offspring weight and adiposity at birth: Examining mediation by maternal fasting glucose in the healthy start study. Environ Health Perspect. 2017;125(6):1-9.

201. Kahn LG, Philippat C, Nakayama SF, Slama R, Trasande L. Endocrine-disrupting chemicals : implications for human health. Lancet Diabetes Endocrinol. 2020;8(8):703-18.

202. Mohajer N, Du CY, Checkcinco C, Blumberg B. Obesogens: How They Are Identi fied and Molecular Mechanisms Underlying Their Action. Front Endocrinol (Lausanne). 2021;12(November):1-22.

203. de Araújo JFP, Podratz PL, Sena GC, Merlo E, Freitas-Lima LC, Ayub JGM, et al. The obesogen tributyltin induces abnormal ovarian adipogenesis in adult female rats. Toxicol Lett [Internet]. 2018;295(February):99-114. Available from: 
https://doi.org/10.1016/j.toxlet.2018.06.1068

204. Abbott DH, Dumesic DA, Levine JE, Angeles L. Hyperandrogenic origins of polycystic ovary syndrome-Implications for Pathophysiology and Therapy. Expert Rev Endocrinol Metab. 2019;14(2):131-43.

205. Grasseli, E. Dvorakova, M. Graceli J. Editorial: Presence and Daily Exposure to Endocrine Disruptors: How Can Human Life Change? Front Endocrinol,. 2021;12(790853):1-2.

206. Fan Y, Pedersen O. Gut microbiota in human metabolic health and disease. Nat Rev Microbiol [Internet]. 2021;19(1):55-71. Available from: http://dx.doi.org/10.1038/s41579-020-0433-9

207. Aguilera M, Gálvez-Ontiveros Y, Rivas A. Endobolome, a New Concept for Determining the Influence of Microbiota Disrupting Chemicals (MDC) in Relation to Specific Endocrine Pathogenesis. Front Microbiol. 2020;11(November).

208. Luo Y, Nie Y, Tang L, Xu CC, Xu L. The correlation between UDP-glucuronosyltransferase polymorphisms and environmental endocrine disruptors levels in polycystic ovary syndrome patients. Medicine (Baltimore). 2020;99(11):e19444.

209. Rosenfeld CS. Xenoestrogen effects on the gut microbiome. Curr Opin Endocr Metab Res [Internet]. 2021;19:41-5. Available from: https://doi.org/10.1016/j.coemr.2021.05.006

210. McDonough CM, Xu HS, Guo TL. Toxicity of bisphenol analogues on the reproductive, nervous, and immune systems, and their relationships to gut microbiome and metabolism: insights from a multi-species comparison. Crit Rev Toxicol [Internet]. 2021;51(4):283-300. Available from: https://doi.org/10.1080/10408444.2021.1908224

211. Mendler A, Geier F, Haange SB, Pierzchalski A, Krause JL, Nijenhuis I, et al. Mucosal-associated invariant T-Cell (MAIT) activation is altered by chlorpyrifos- and glyphosate-treated commensal gut bacteria. J Immunotoxicol [Internet]. 2020;17(1):10-20. Available from: https://doi.org/10.1080/1547691X.2019.1706672

212. Clair E, Linn L, Travert C, Amiel C, Séralini GE, Panoff JM. Effects of roundup® and glyphosate on three food microorganisms: Geotrichum candidum, Lactococcus lactis subsp. cremoris and lactobacillus delbrueckii subsp. bulgaricus. Curr Microbiol. 2012;64(5):486-91.

213. Tang Q, Tang J, Ren X, Li C. Glyphosate exposure induces inflammatory responses in the small intestine and alters gut microbial composition in rats. Environ Pollut [Internet]. 2020;261:114129. Available from: https://doi.org/10.1016/j.envpol.2020.114129

214. Rueda-Ruzafa L, Cruz F, Roman P, Cardona D. Gut microbiota and neurological effects of glyphosate. Neurotoxicology. 2019;75(August):1-8.

215. Choi YJ, Seelbach MJ, Pu H, Eum SY, Chen L, Zhang B, et al. Polychlorinated biphenyls disrupt intestinal integrity via NADPH oxidase-induced alterations of tight junction protein expression. Environ Health Perspect. 2010;118(7):976-81.

216. Kim HG, Yeon S min, Kim KH, Kim H, Park J Il, Kang HJ, et al. Estrogenic Endocrine-Disrupting Chemicals Modulate the Production of Inflammatory Mediators and Cell Viability of Lipopolysaccharide-Stimulated Macrophages. Inflammation. 2015;38(2):595-605.

217. Linares R, Fernández MF, Gutiérrez A, García-Villalba R, Suárez B, Zapater P, et al. Endocrine disruption in Crohn's disease: Bisphenol A enhances systemic inflammatory response in patients with gut barrier translocation of dysbiotic microbiota products. FASEB J. 2021;35(7):1-13.

218. HAMPL R, STARKA L. Endocrine Disruptors and Gut Microbiome Interactions. Physiol Res. 2020;69:S211-23.

219. Endocrine Society. Position Statement: Endocrine-Disrupting Chemicals. Endocrinology. 2018;153(September).

220. Gore AC, Chappell VA, Fenton SE, Flaws JA, Nadal A, Prins GS, et al. EDC-2: The Endocrine Society's Second Scientific Statement on Endocrine-Disrupting Chemicals. Endocr Rev. 2015;36(6):1-150.

221. Rubin BS, Schaeberle CM, Soto AM. The case for BPA as an obesogen: Contributors to the controversy. Front Endocrinol (Lausanne). 2019;10(FEB):1-11.

222. Lee DH, Porta M, Jacobs DR, Vandenberg LN. Chlorinated persistent organic pollutants, obesity, and type 2 diabetes. Endocr 
Rev. 2014;35(4):557-601.

223. de Araújo JFP, Podratz PL, Sena GC, Merlo E, Freitas-Lima LC, Ayub JGM, et al. The obesogen tributyltin induces abnormal ovarian adipogenesis in adult female rats. Toxicol Lett [Internet]. 2018;295(June):99-114. Available from: https://doi.org/10.1016/j.toxlet.2018.06.1068

224. Kahn LG, Philippat C, Nakayama SF, Slama R, Trasande L. Endocrine-disrupting chemicals: implications for human health. Vol. 8, The Lancet Diabetes and Endocrinology. 2020. p. 703-18.

225. Cardenas A, Hauser R, Gold DR, Kleinman KP, Hivert MF, Fleisch AF, et al. Association of Perfluoroalkyl and Polyfluoroalkyl Substances with Adiposity. JAMA Netw Open. 2018;1(4):1-15.

226. Liu G, Dhana K, Furtado JD, Rood J, Zong G, Liang L, et al. Perfluoroalkyl substances and changes in body weight and resting metabolic rate in response to weight-loss diets: A prospective study. PLoS Med. 2018;15(2):1-21.

227. FIGO Statement on PFAS (accessed 17 November 2021). https://www.figo.org/figo-calls-removal-pfas-global-use.

228. Yang Z, Shi J, Guo Z, Chen M, Wang C, He C, et al. A pilot study on polycystic ovarian syndrome caused by neonatal exposure to tributyltin and bisphenol $A$ in rats. Chemosphere [Internet]. 2019;231:151-60. Available from: https://doi.org/10.1016/j.chemosphere.2019.05.129

229. Ye J, Zhu W, Liu H, Mao Y, Jin F, Zhang J. Environmental exposure to triclosan and polycystic ovary syndrome: A crosssectional study in China. BMJ Open. 2018;8(10):1-7.

230. Kassotis CD, Vandenberg LN, Demeneix BA, Porta M, Slama R, Trasande L. Endocrine-disrupting chemicals: economic, regulatory, and policy implications. Lancet Diabetes Endocrinol [Internet]. 2020;8(8):719-30. Available from: http://dx.doi.org/10.1016/S2213-8587(20)30128-5

231. Resnik DB. The precautionary principle and medical decision making. J Med Philos. 2004;29(3):281-99.

232. Di Renzo GC, Conry JA, Blake J, Defrancesco MS, Denicola N, Martin JN, et al. International Federation of Gynecology and Obstetrics opinion on reproductive health impacts of exposure to toxic environmental chemicals. Int J Gynecol Obstet. 2015;131(3):219-25.

233. Bellingham M, Sharpe R. Chemical Exposures During Pregnancy: Dealing with Potential, but Unproven, Risks to Child Health. R Coll Obstet Gynaecol [Internet]. 2013;(37). Available from: http://www.rcog.org.uk/files/rcogcorp/5.6.13ChemicalExposures.pdf

234. Moran, Lisa. Hutchison, Samantha K. Norman RJ, Teede HJ. Lifestyle changes in women with polycystic ovary syndrome. Cochrane Database Syst Rev. 2019;2019(3).

235. Lim SS, Hutchison SK, Van Ryswyk E, Norman RJ, Teede HJ, Moran LJ. Lifestyle changes in women with polycystic ovary syndrome. Cochrane Database Syst Rev. 2019;2019(3).

236. Shishehgar F, Ramezani Tehrani F, Mirmiran P, Hajian S, Baghestani AR, Moslehi N. Comparison of Dietary Intake between Polycystic Ovary Syndrome Women and Controls. Glob J Health Sci. 2016;8(9):302.

237. Rajska A, Buszewska-Forajta M, Rachoń D, Markuszewski MJ. Metabolomic insight into polycystic ovary syndrome-An overview. Int J Mol Sci. 2020;21(14):1-21.

238. Parker J, O'Brien C, Hawrelak J. A review of the role of gastrointestinal dysbiosis in the pathogenesis of polycystic ovary syndrome. Preprint. 2021;

239. Jankovic N, Geelen A, Streppel MT, De Groot LCPGM, Orfanos P, Van Den Hooven EH, et al. Adherence to a healthy diet according to the world health organization guidelines and all-cause mortality in elderly adults from Europe and the United States. Am J Epidemiol. 2014;180(10):978-88.

240. Kim, Hyunju Rebholz CM. Metabolomic biomarkers of healthy dietary patterns and cardiovascular outcomes. Curr Atheroscler Rep. 2021;23(6):26.

241. Andrews P, Johnson RJ. Evolutionary basis for the human diet: consequences for human health. J Intern Med. 
2020;287(3):226-37.

242. Osiecki H. Contingent nutrient factors. In: Osiecki H, editor. The Nutrient Bible. 9th ed. Queensland: AG Publishing; 2014. p. 217.

243. Pandey KB, Rizvi SI. Plant polyphenols as dietary antioxidants in human health and disease. Oxid Med Cell Longev. 2009;2(5):270-8.

244. Moorthy M, Chaiyakunapruk N, Jacob SA, Palanisamy UD. Prebiotic potential of polyphenols, its effect on gut microbiota and anthropometric/clinical markers: A systematic review of randomised controlled trials. Trends Food Sci Technol [Internet]. 2020;99(February):634-49. Available from: https://doi.org/10.1016/j.tifs.2020.03.036

245. Cao H, Chen X, Jassbi AR, Xiao J. Microbial biotransformation of bioactive flavonoids. Biotechnol Adv [Internet]. 2015;33(1):214-23. Available from: http://dx.doi.org/10.1016/j.biotechadv.2014.10.012

246. Luca SV, Macovei I, Bujor A, Miron A, Skalicka-Woźniak K, Aprotosoaie AC, et al. Bioactivity of dietary polyphenols: The role of metabolites. Crit Rev Food Sci Nutr [Internet]. 2020;60(4):626-59. Available from: https://doi.org/10.1080/10408398.2018.1546669

247. Tehrani, HG. Allahdadian, M. Zarre, F. Ranjbar, H. Allahdadian F. Effect of green tea on metabolic and hormonal aspect of polycystic ovary syndrome in overweight and obese women suffering from polycystic ovary syndrome: A clinical trial. J Educ Health Promot. 2017;6(May).

248. Zilaee M, Mansoori A, Ahmad HS, Mohaghegh SM, Asadi M, Hormoznejad R. The effects of soy isoflavones on total testosterone and follicle-stimulating hormone levels in women with polycystic ovary syndrome: a systematic review and meta-analysis. Eur J Contracept Reprod Heal Care [Internet]. 2020;25(4):305-10. Available from: https://doi.org/10.1080/13625187.2020.1761956

249. Chien YJ, Chang CY, Wu MY, Chen CH, Horng YS, Wu HC. Effects of curcumin on glycemic control and lipid profile in polycystic ovary syndrome: Systematic review with meta-analysis and trial sequential analysis. Nutrients. 2021;13(2):1-14.

250. Abedini M, Ghasemi-Tehrani H, Tarrahi MJ, Amani R. The effect of concentrated pomegranate juice consumption on risk factors of cardiovascular diseases in women with polycystic ovary syndrome: A randomized controlled trial. Phyther Res. 2021;35(1):442-51.

251. Jew S, Abumweis SS, Jones PJH. Evolution of the human diet: Linking our ancestral diet to modern functional foods as a means of chronic disease prevention. J Med Food. 2009;12(5):925-34.

252. London DS, Beezhold B. A phytochemical-rich diet may explain the absence of age-related decline in visual acuity of Amazonian hunter-gatherers in Ecuador. Nutr Res [Internet]. 2015;35(2):107-17. Available from: http://dx.doi.org/10.1016/j.nutres.2014.12.007

253. Clayton P, Rowbotham J. An unsuitable and degraded diet? Part two: Realities of the mid-Victorian diet. J R Soc Med. 2008;101(7):350-7.

254. Khani B, Mehrabian F, Khalesi E, Eshraghi A. Original Article Effect of soy phytoestrogen on metabolic and hormonal disturbance of women with polycystic ovary syndrome. 2011;16(3):297-302.

255. Pontzer H, Wood BM, Raichlen DA. Hunter-gatherers as models in public health. Obes Rev. 2018;19(December):24-35.

256. Fayet-Moore F, Cassettari T, Tuck K, McConnell A, Petocz P. Dietary fibre intake in australia. Paper i: Associations with demographic, socio-economic, and anthropometric factors. Nutrients. 2018;10(5):1-16.

257. Satija A, Hu FB. Cardiovascular benefits of dietary fiber. Curr Atheroscler Rep. 2012;14(6):505-14.

258. Müller M, Canfora EE, Blaak EE. Gastrointestinal transit time, glucose homeostasis and metabolic health: Modulation by dietary fibers. Nutrients. 2018;10(3).

259. Lattimer JM, Haub MD. Effects of dietary fiber and its components on metabolic health. Nutrients. 2010;2(12):1266-89.

260. Ghanim H, Batra M, Abuaysheh S, Green K, Makdissi A, Kuhadiya ND, et al. Antiinflammatory and ROS Suppressive Effects 
of the Addition of Fiber to a High-Fat High-Calorie Meal. J Clin Endocrinol Metab. 2017;102(3):858-69.

261. Thompson S V., Hannon BA, An R, Holscher HD. Effects of isolated soluble fiber supplementation on body weight, glycemia, and insulinemia in adults with overweight and obesity: A systematic review and meta-analysis of randomized controlled trials. Am J Clin Nutr. 2017;106(6):1514-28.

262. Veronese N, Solmi M, Caruso MG, Giannelli G, Osella AR, Evangelou E, et al. Dietary fiber and health outcomes: An umbrella review of systematic reviews and meta-analyses. Am J Clin Nutr. 2018;107(3):436-44.

263. Cutler DA, Pride SM, Cheung AP. Low intakes of dietary fiber and magnesium are associated with insulin resistance and hyperandrogenism in polycystic ovary syndrome: A cohort study. Food Sci Nutr. 2019;7(4):1426-37.

264. Holscher HD. Dietary fiber and prebiotics and the gastrointestinal microbiota. Gut Microbes [Internet]. 2017;8(2):172-84. Available from: http://dx.doi.org/10.1080/19490976.2017.1290756

265. Al-Assal K, Martinez AC, Torrinhas RS, Cardinelli C, Waitzberg D. Gut microbiota and obesity. Clin Nutr Exp [Internet]. 2018;20:60-4. Available from: https://doi.org/10.1016/j.yclnex.2018.03.001

266. Verdam FJ, Fuentes S, De Jonge C, Zoetendal EG, Erbil R, Greve JW, et al. Human intestinal microbiota composition is associated with local and systemic inflammation in obesity. Obesity. 2013;21(12):607-15.

267. Torres PJ, Siakowska M, Banaszewska B, Pawelczyk L, Duleba AJ, Kelley ST, et al. Gut Microbial Diversity in Women With Polycystic Ovary Syndrome Correlates With Hyperandrogenism. J Clin Endocrinol Metab [Internet]. 2018/01/26. 2018;103(4):1502-11. Available from: https://www.ncbi.nlm.nih.gov/pubmed/29370410

268. Eaton SB, Konner M, Shostak M. Stone agers in the fast lane: Chronic degenerative diseases in evolutionary perspective. Am J Med. 1988;84(4):739-49.

269. Hill B, Bergmeier H, Incollingo Rodriguez AC, Barlow FK, Chung A, Ramachandran D, et al. Weight stigma and obesityrelated policies: A systematic review of the state of the literature. Obes Rev. 2021;22(11):1-10.

270. Submission to the National Obesity Prevention Strategy. https://preventioncentre.org.au/wp-content/uploads/2021/11/CERIsubmission-National-Obesity-Prevention-Strategy.pdf. 2021.

271. Lepre B, Mansfield KJ, Ray S, Beck EJ. Nutrition competencies for medicine: An integrative review and critical synthesis. BMJ Open. 2021;11(3):1-12. 